\title{
Producción y exportación de vino en España: El caso de Castilla y León
}

\author{
JUAN JOSÉ JUSTE CARRIÓN \\ Universidad de Valladolid, Facultad de Ciencias Económicas y Empresariales, Avda. del Valle \\ Esgueva, 6, 47011 Valladolid, España.E-mail: juste@eco.uva.es
}

\begin{abstract}
RESUMEN
La industria agroalimentaria (IAA) constituye una de las principales ramas del sector manufacturero en Castilla y León y en España y una de las actividades que mejor comportamiento ha venido registrando en estos últimos años de dura crisis económica. Tales circunstancias confieren a este sector la condición de importante motor de desarrollo económico territorial. Dentro de la IAA, el subsector del vino ha experimentado un considerable dinamismo, hasta colocar a España como principal país exportador a nivel mundial. El objetivo fundamental del presente trabajo es reflejar la andadura del subsector vinícola en la región de Castilla y León, con particular referencia a su actividad exportadora. Para ello, se examinará la posición de la industria española del vino a escala mundial, su relevancia en el contexto agroalimentario nacional y su comportamiento en los últimos años. Después, se analizará el caso particular de esta rama manufacturera en Castilla y León, haciendo hincapié en sus potencialidades como vehículo de internacionalización, merced a la creciente exportación, y como elemento de desarrollo local/rural.
\end{abstract}

Palabras clave: Industria vinícola, exportaciones, industria agroalimentaria, territorio, desarrollo local/rural.

\section{Spains's Wine Production and Exports: The Case of Castile and Leon}

\begin{abstract}
The agrofood industry (AFI) is one of the main branches of the manufacturing sector in Castile and Leon and Spain and one of the best performing activities in recent years of severe economic crisis. In these circumstances this industry appears as an important factor for territorial economic development. Within the AFI, the wine subsector has experienced considerable dynamism, placing Spain as the main exporting country worldwide in volume. The main objective of this work is to analyze the evolution of the wine subsector in the region of Castile and Leon, with particular reference to its export activity. In order to achieve this purpose, the position of the Spanish wine industry at the global level, its relevance in the national agrofood context and its performance in recent years are examined. After that, the particular case of this manufacturing sector in Castile and Leon will be analyzed, emphasizing its potential as a vehicle for both internationalization, thanks to the increasing export, and local/rural development.
\end{abstract}

Keywords: Wine Industry, Exports, Agrofood Industry, Territory, Local/Rural Development.

Clasificación JEL: L66, O18, R10, R50

Artículo recibido en octubre de 2016 y aceptado en diciembre de 2016

Artículo disponible en versión electrónica en la página www.revista-eea.net, ref. ə-35109 


\section{INTRODUCCIÓN}

La industria agroalimentaria (IAA) constituye una de las principales ramas del tejido industrial español, tanto en términos de VAB y producción, como de empleo. Con todo, su relevancia resulta dispar en la geografía nacional, alcanzando una especial significación determinadas regiones, como Andalucía, Cataluña y también Castilla y León, en la cual el sector, a la vez que pilar básico de crecimiento manufacturero, aparece como inestimable elemento de desarrollo territorial, al sustentar múltiples procesos de desarrollo rural/local en curso.

Dentro de la IAA, un subsector estratégico por excelencia es, sin duda, el vinícola, cuyo notable dinamismo en los últimos años, a escala regional y nacional, ha situado a España a la cabeza del ranking de países exportadores. Algunas regiones, como Castilla-La Mancha, La Rioja, Cataluña, la Comunidad Valenciana, el País Vasco o Castilla y León vienen contribuyendo a ello de manera especialmente intensa, con una creciente orientación de sus ventas hacia el exterior.

El objetivo fundamental del presente trabajo es analizar el comportamiento reciente de dicho subsector en España y, sobre todo, en Castilla y León, con particular referencia a su actividad exportadora.

Para ello, en primer lugar, se mostrará como telón de fondo, la posición de la industria vinícola española en el contexto mundial. En segundo lugar, se examinará su situación actual en términos de producción, consumo y exportación, tomando como punto de partida su considerable peso dentro de la IAA nacional, avalado por la importancia económica y social de la vitivinicultura y su amplia dispersión geográfica, con presencia en numerosos núcleos de población rurales, algunos de los cuales configuran sistemas productivos locales (SPL), a menudo ligados a la producción de vinos de calidad con fuerte vinculación al territorio. En tercer lugar, se analizará el caso particular de esta rama manufacturera en Castilla y León, haciendo hincapié en su potencial como motor de internacionalización, merced a la creciente actividad exportadora, y como instrumento de desarrollo local/rural, con especial proyección en algunos sistemas productivos locales agroalimentarios (SPLA) de la región. El trabajo se cerrará con una serie de conclusiones y consideraciones finales relativas al futuro del sector.

La información estadística utilizada procede, esencialmente, del Observatorio Español del Mercado del Vino (OEMV), del Ministerio de Agricultura, Alimentación y Medio Ambiente (MAGRAMA) y de la Encuesta Industrial de Empresas del INE.

\section{LA INDUSTRIA DEL VINO EN ESPAÑA}

La tradición vitivinícola hunde sus raíces en el pasado más remoto de la Europa Mediterránea, convirtiendo al vino en parte integral de su cultura 
alimentaria (Unwin, 2001; Sánchez Hernández, 2014; Fernández y Pinilla, 2014). España, constituye desde hace mucho tiempo, junto a Francia e Italia, uno de los principales países productores de vino a escala mundial y, en los últimos años, uno de los mayores exportadores. En aras de mostrar la gran importancia económica de esta actividad, a continuación se muestra su posición general dentro del contexto internacional, así como su peso dentro del contexto de la IAA nacional, y se identifican sus principales rasgos en relación con variables como la producción, el consumo y la actividad exportadora.

\subsection{La industria vitivinícola española en el contexto internacional}

La industria vitivinícola española ocupa una privilegiada posición a escala mundial. Así queda reflejado en la Figura 1, de cuya observación cabe destacar, con datos de 2015, tres aspectos:

- La gran extensión de terreno dedicado al cultivo de la vid, como materia prima. No en vano, con cerca de un millón de hectáreas de cultivo, repartidas por toda la geografía nacional, España es el primer país del mundo en cuanto a superficie de viñedo, representando en torno al $13 \%$ del total mundial, seguida de Francia, Italia y China ${ }^{1}$.

Figura 1

Principales países productores de vino, 2015 (\% sobre total mundial)

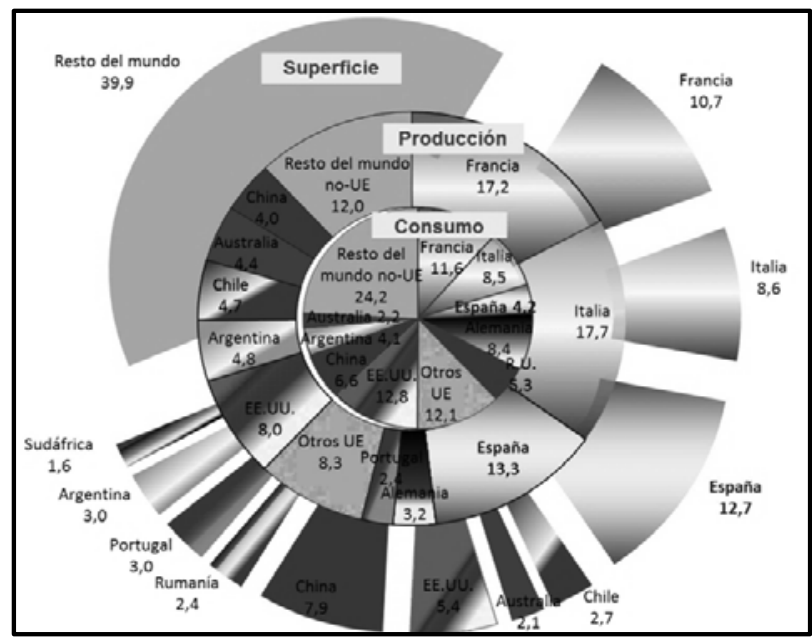

Fuente: Elaboración propia, a partir de los datos del Observatorio Español del Mercado del Vino.

${ }^{1}$ Desde los años 70, la superficie mundial de viñedo se ha reducido en unos 2 millones de hectáreas, afectando, sobre todo, al área de la UE (España ha perdido unas 700.000 hectáreas). Asia y América Latina han ido incrementando sus extensiones de cultivo de la vid, destacando China, que ha pasado de 200.000 hectáreas, en 2000, a 800.000, en 2015. 
- El elevado volumen de producción. España figura entre los principales productores de vino a nivel internacional. Con alrededor de 37,5 millones de hectolitros obtenidos en 2015 (el 13\% de la producción mundial), viene ocupando la tercera posición tras Italia y Francia, a notable distancia del siguiente país en el ranking: Estados Unidos.

- Un importante volumen de consumo interno. Sin embargo, respecto a esta variable, nuestro país se sitúa en séptima posición, concentrando tan sólo el 4,2\% del consumo mundial de vino, en claro contraste con los porcentajes anteriores; una cifra, en todo caso, muy inferior a la de países como Estados Unidos (12,8\%, dado su tamaño demográfico), Francia (11,6\%), Italia (8,5\%) e incluso Alemania, Reino Unido o China, y similar a la de Argentina. De hecho, el consumo per cápita español (17,25 litros anuales por persona en 2015: unas 23 botellas) dista notablemente de los niveles alcanzados en Italia (58 botellas), Francia (57), Portugal (56), Dinamarca (55), Bélgica (39), Alemania (34) e incluso Reino Unido (27).

Figura 2

Principales países exportadores de vino, 2015

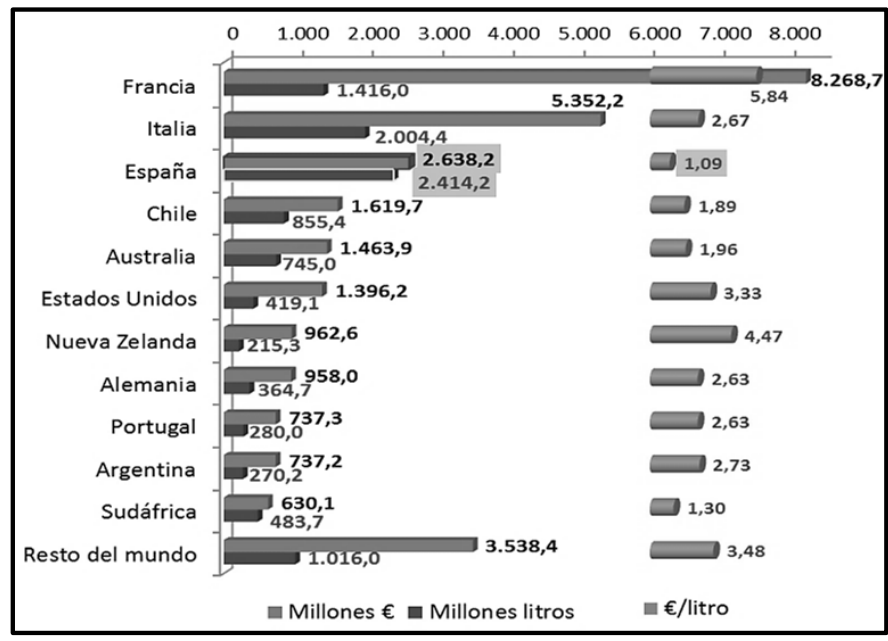

Fuente: Observatorio Español del Mercado del Vino.

Por lo que atañe a las exportaciones, como se recoge en la Figura 2, el creciente dinamismo exportador ha llevado a España a alcanzar, en 2015, el primer puesto en el ranking de países exportadores de vino, con más de 2.400 millones de litros, por delante de Italia y Francia. Esto supone el 23\% de las exportaciones mundiales en volumen. Sin embargo, en términos de valor, la exportación española (casi 2.640 millones de euros), tan sólo supone el 9,3\% del total mundial, muy inferior a la francesa $(29,2 \%)$ e italiana $(18,9 \%)$. Ello se 
debe al bajo precio medio de exportación del vino nacional, 1,09 euros por litro -buena parte vendido aún a granel-, en contraste con los precios de países como Francia (sinónimo de calidad y prestigio en el mercado internacional ya desde el siglo XIX), Nueva Zelanda o Estados Unidos, entre otros.

\subsection{La industria del vino dentro de la IAA española}

Tal y como se aprecia en la Tabla 1, la IAA española presenta una notable concentración sectorial. Destaca singularmente el subsector Industrias cárnicas, que con 83.400 empleos y 20.000 millones de facturación (el 23,5\% y el 21,5\% del total del sector, respectivamente), lidera el conjunto de variables consideradas, a excepción del número de empresas. Otras ramas agroalimentarias importantes son: Pan, pastelería, galletas y pastas alimenticias, en cuanto a número de unidades productivas, empleo, gastos de personal y valor añadido; Grasas y aceites, en volumen de ventas y consumo de materias primas; y Conservas vegetales, en cuanto a empleo y ventas e inversión en activos materiales realizadas en 2014.

Tabla 1

Principales indicadores de la IAA española por ramas, 2014

\begin{tabular}{|c|c|c|c|c|c|c|c|c|c|c|}
\hline SUBSECTORES & \begin{tabular}{|c|}
$\begin{array}{c}\text { Número } \\
\text { de } \\
\text { Empresas }\end{array}$ \\
\end{tabular} & Empleo & $\begin{array}{l}\text { Ventas netas } \\
\text { de Producto } \\
\text { (millones } € \text { ) } \\
\end{array}$ & \begin{tabular}{|c|} 
Consumo \\
Mater. Primas \\
(millones $€$ ) \\
\end{tabular} & $\begin{array}{c}\text { Inversión } \\
\text { Activos Mat. } \\
\text { (millones } € \text { ) } \\
\end{array}$ & $\begin{array}{c}\text { Valor } \\
\text { Añadido } \\
\text { (millones } € \text { ) }\end{array}$ & $\begin{array}{c}\text { Gastos } \\
\text { de Personal } \\
\text { (millones } € \text { ) } \\
\end{array}$ & $\begin{array}{c}\text { Coste Lab. I } \\
\text { Empleado } \\
\text { (euros) }\end{array}$ & $\begin{array}{l}\text { Valor Añad.I } \\
\text { Empleado } \\
\text { (euros) }\end{array}$ & $\begin{array}{c}\text { Tamaño } \\
\text { Medio de } \\
\text { Empresas } \\
\end{array}$ \\
\hline \multirow{2}{*}{$\begin{array}{l}\text { Industrias Cárnicas } \\
\text { Transformación de } \\
\text { Pescado }\end{array}$} & 3.926 & 83.407 & 20.079 & 13.571 & 527 & 4.022 & 2.238 & 26.832 & 48.221 & 21,2 \\
\hline & 656 & 18.339 & 4.166 & 2.754 & 94 & 794 & 436 & 23.774 & 43.296 & 28,0 \\
\hline Conservas Vegetales & 1.353 & 31.069 & 8.247 & 4.713 & 423 & 1.568 & 841 & 27.069 & 50.468 & 23,0 \\
\hline Grasas y Aceites & 1.605 & 11.874 & 10.262 & 8.794 & 170 & 1.056 & 394 & 33.182 & 88.934 & 7,4 \\
\hline \multirow{6}{*}{$\begin{array}{l}\text { Industrias Lácteas } \\
\text { Productos de } \\
\text { Molinería } \\
\text { Pan, Pastelería, } \\
\text { Pastas aliment. } \\
\text { Azúcar, Chocolate y } \\
\text { Confitería } \\
\text { Otros Productos } \\
\text { Diversos } \\
\text { Prod. de Alimentación } \\
\text { Animal } \\
\end{array}$} & 1.536 & 24.340 & 8.643 & 5.159 & 92 & 1.600 & 859 & 35.292 & 65.735 & 15,8 \\
\hline & 492 & 5.900 & 2.932 & 2.180 & 43 & 471 & 227 & 38.475 & 79.831 & 12,0 \\
\hline & 10.314 & 76.921 & 6.567 & 2.337 & 238 & 2.483 & 1.645 & 21.386 & 32.280 & 7,5 \\
\hline & 714 & 14.524 & 3.455 & 1.728 & 50 & 856 & 518 & 35.665 & 58.937 & 20,3 \\
\hline & 1.897 & 30.779 & 6.848 & 3.349 & 289 & 1.780 & 1.074 & 34.894 & 57.832 & 16,2 \\
\hline & 812 & 11.752 & 8.819 & 6.770 & 138 & 1.076 & 434 & 36.930 & 91.559 & 14,5 \\
\hline Vinos & 4.047 & 24.793 & 5.844 & 2.732 & 371 & 1.674 & 759 & 30.613 & 67.519 & 6,1 \\
\hline \multirow{2}{*}{$\begin{array}{l}\text { Otras Bebidas } \\
\text { Alcohólicas } \\
\text { Aguas y Bebidas } \\
\text { Alcohólicas }\end{array}$} & 701 & 9.317 & 3.737 & 881 & 303 & 1.331 & 566 & 60.749 & 142.857 & 13,3 \\
\hline & 319 & 10.949 & 3.796 & 2.129 & 62 & 1.012 & 514 & 46.945 & 92.429 & 34,3 \\
\hline TOTAL IAA ESPAÑA & 28.372 & 353.964 & 93.395 & 57.097 & 2.800 & 19.723 & 10.505 & 29.678 & 55.720 & 12,5 \\
\hline $\begin{array}{l}\text { TOTAL INDUSTRIA } \\
\text { ESPAÑA }\end{array}$ & 99.483 & 1.931 .972 & 454.966 & 216.712 & 15.677 & 127.547 & 69.659 & 36.056 & 66.019 & 9,7 \\
\hline
\end{tabular}

Fuente: Elaboración propia, a partir de INE: Encuesta Industrial de Empresas.

El subsector Vinos da empleo en ese año a casi 24.800 personas (el 7\% de la ocupación total en la IAA nacional), distribuidas entre algo más de 4.000 empresas (14,3\% del total), y genera unas ventas de más de 5.800 millones de euros, muy por encima de los otros dos subsectores de bebidas: alcohólicas y analcohólicas. Es una de las ramas de mayor valor añadido (8,5\% del total), registrando asimismo ratios de coste laboral por empleado y productividad 
mejores que la media de la IAA española; ello se traduce en un coste laboral unitario ( $0,45 €$ por euro producido) más favorable que en la mayoría de actividades agroalimentarias. Con todo, el tamaño medio de las empresas vinícolas -6,1 trabajadores- es significativamente reducido, inferior, de hecho, al del resto de subsectores de la IAA.

\subsection{Rasgos fundamentales del subsector del vino a escala nacional}

A la hora de caracterizar el sector del vino en España, cabe señalar los siguientes aspectos:

1) La fuerte concentración regional del cultivo de la vid, destacando singularmente Castilla-La Mancha. Así, en 2014, con una superficie total de 442.829 hectáreas, dicha región representa nada menos que el 47,6\% de la superficie nacional de viñedo de uva para vinificación. En segunda posición se sitúa Extremadura, con 81.405 hectáreas (8,7\%). Otras regiones importantes son la Comunidad Valenciana (62.292), Cataluña (54.966) y La Rioja (45.991).

2) Las importantes variaciones de la producción entre añadas. Como muestra la Tabla 2, la producción vinícola nacional fluctúa notablemente de año en año, en función de las oscilaciones climáticas, que determinan la temperatura, humedad y nivel hídrico del suelo, con evidentes efectos en la cantidad y calidad de la uva recogida. Con todo, pese a la reducción de la superficie de cultivo, la producción media de vino y mosto permanece bastante estable. Por regiones, dicha evolución resulta dispar. En algunas, las fluctuaciones anuales a lo largo de los tres últimos lustros se saldan -tomando la media y la mediana para el periodo- con una tendencia netamente ascendente (Aragón, Baleares, Extremadura, País Vasco), o ligeramente creciente (Castilla y León); otras, en cambio, experimentan un rumbo general descendente: Madrid, Andalucía, Canarias, Galicia o Asturias.

En cualquier caso, como se aprecia en la Figura 3, hay regiones con tasas de variación anual altamente volátiles, como Castilla-La Mancha, Galicia, Aragón, la Comunidad Valenciana (además de Canarias) y otras con mayor estabilidad, como Cataluña, La Rioja o Castilla y León. Un interrogante abierto en este ámbito, es el potencial impacto del cambio climático en la producción final de uva y en la calidad de los caldos a escala regional. 


\section{Tabla 2}

Evolución de la producción española de vino, por regiones: 2000-2015

(miles de hectolitros) (mosto incluido)

\begin{tabular}{|c|c|c|c|c|c|c|c|c|c|c|c|c|c|c|c|c|}
\hline REGIONES & 2000 & 2001 & 2002 & 2003 & 2004 & 2005 & 2006 & 2007 & 2008 & 2009 & 2010 & 2011 & 2012 & 2013 & 2014 & 2015 \\
\hline Andalucía & 1.873 & 1.950 & 1.821 & 1.900 & 2.080 & 1.265 & 1.246 & 1.709 & 1.412 & 1.350 & 1.315 & 1.369 & 1.141 & 1.412 & 1.087 & 1.187 \\
\hline Aragón & 1.029 & 777 & 848 & 1.193 & 1.629 & 1.115 & 1.400 & 1.571 & 898 & 1.406 & 1.117 & 1.148 & 1.000 & 1.037 & 1.123 & 1.452 \\
\hline Asturias & 1 & 3 & 4 & 4 & 4 & 4 & 4 & 3 & 2 & 2 & 1 & 2 & 1 & 1 & ${ }^{2}$ & 2 \\
\hline Baleares & 28 & 38 & 31 & 53 & 42 & 44 & 46 & 45 & 36 & 43 & 46 & 35 & 41 & 46 & 49 & 58 \\
\hline Canarias & 205 & 183 & 154 & 195 & 159 & 184 & 219 & 26 & 144 & 101 & 60 & 86 & 78 & 128 & 126 & 103 \\
\hline Cantabria & 1 & 1 & 1 & 1 & 1 & 1 & 1 & 1 & 1 & 1 & 5 & 1 & 1 & 1 & 1 & 1 \\
\hline Castilla y Leó & 1.668 & 1.317 & 1.405 & 1.721 & 1.870 & 1.671 & 2.014 & 1.621 & 1.452 & 1.471 & 1.581 & 1.825 & 1.896 & 2.078 & 2.268 & 1.843 \\
\hline \begin{tabular}{|l|} 
Castilla-La \\
Mancha \\
\end{tabular} & 24.542 & 15.977 & 21.100 & 25.528 & 26.300 & 21.682 & 23.282 & 21.501 & 23.056 & 18.995 & 21.568 & 18.622 & 19.032 & 33.030 & 25.123 & 22.9 \\
\hline Cataluña & 3.143 & 2.980 & 3.389 & 3.692 & 4.045 & 2.719 & 3.271 & 3.197 & 3.238 & 3.512 & 3.483 & 3.293 & 2.784 & 3.744 & 3.289 & 3.311 \\
\hline \begin{tabular}{|l|} 
Comunidad \\
Valenciana
\end{tabular} & 2.347 & 2.150 & 2.996 & 3.500 & 2.711 & 2.692 & 2.671 & 2.761 & 2.310 & 2.810 & 2.249 & 2.341 & 2.151 & 3.004 & 1.965 & 2.7 \\
\hline Extremadura & 3.684 & 2.873 & 3.528 & 4.621 & 4.058 & 3.214 & 3.048 & 2.973 & 3.664 & 3.127 & 3.903 & 4.282 & 3.191 & 4.181 & 4.272 & 4.051 \\
\hline Galicia & 1.048 & 1.442 & 1.423 & 1.785 & 1.912 & 1.738 & 1.600 & 1.880 & 1.018 & 888 & 909 & 1.500 & 741 & 739 & 679 & 871 \\
\hline Madrid & 330 & 444 & 533 & 642 & 277 & 268 & 431 & 234 & 325 & 143 & 180 & 122 & 90 & 178 & 134 & 122 \\
\hline Murcia & 605 & 585 & 799 & 698 & 609 & 575 & 609 & 705 & 675 & 681 & 907 & 675 & 675 & 944 & 624 & 679 \\
\hline Navarra & 1.700 & 772 & 690 & 933 & 1.232 & 981 & 1.071 & 1.087 & 769 & 850 & 822 & 680 & 591 & 684 & 730 & 849 \\
\hline País Vasco & 744 & 589 & 410 & 637 & 706 & 661 & 662 & 626 & 577 & 756 & 647 & 601 & 528 & 591 & 825 & 780 \\
\hline Rioja (La) & 2.622 & 1.857 & 1.419 & 2.236 & 2.427 & 2.304 & 2.085 & 2.200 & 2.007 & 2.125 & 2.101 & 2.003 & 1.836 & 1.753 & 2.120 & 2.271 \\
\hline ESPAÑA & 45.572 & 33.937 & 40.549 & 49.339 & 50.062 & 41.119 & 43.659 & 42.141 & 41.583 & 38.259 & 40.892 & 38.583 & 35.778 & 53.550 & 44.415 & 43.28 \\
\hline
\end{tabular}

FUENTE: Observatorio Español del Mercado del Vino.

Figura 3

Variación anual de la producción vinícola en las principales regiones productoras (\%)

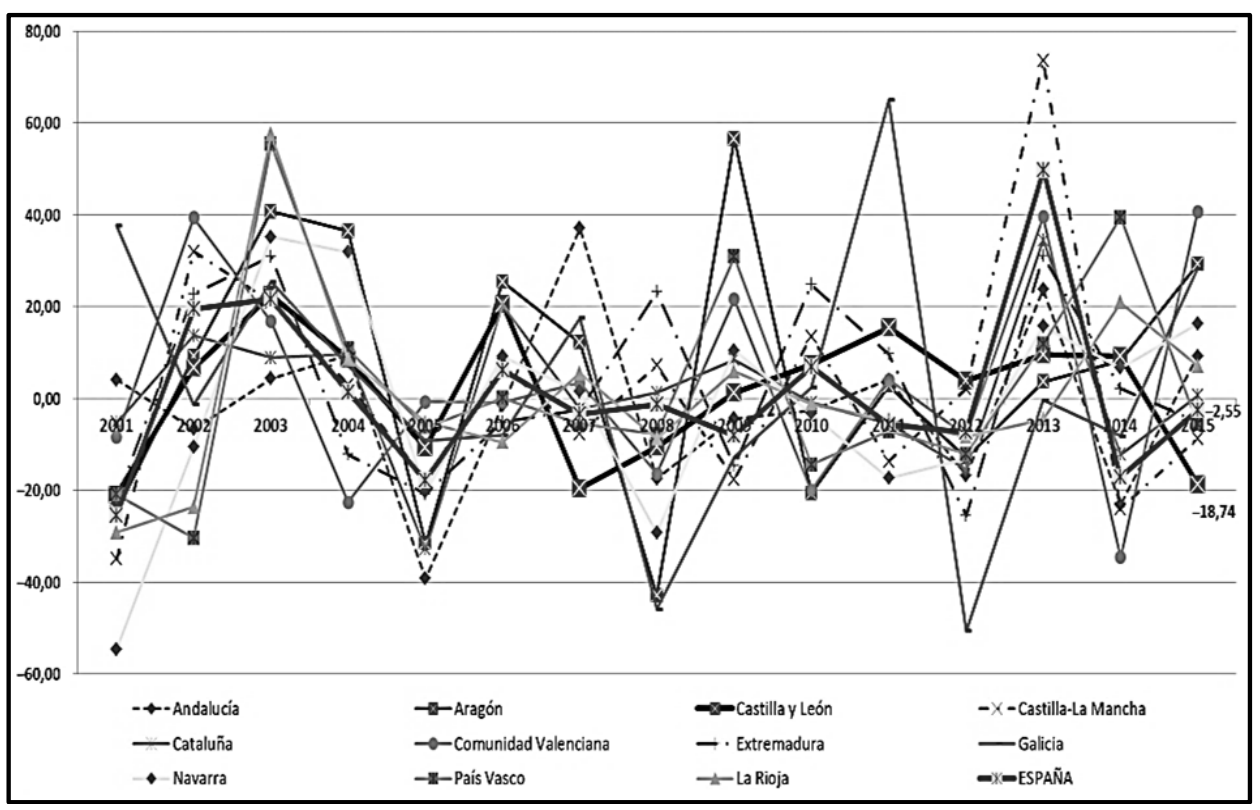

Fuente: Elaboración propia, a partir de los datos del Observatorio Español del Mercado del Vino. 
3) La gran concentración geográfica de la producción. En línea con lo señalado respecto a la superficie de cultivo, tan sólo Castilla-La Mancha, principal territorio, aglutina hasta un 53\% del output total de vino y mosto, considerando la producción conjunta media del periodo 2000-2015 (Figura 4). Le siguen en importancia Extremadura, Cataluña y la Comunidad Valenciana. La entidad de dicho cuarteto ( $75,5 \%$ del total), contrasta claramente con la del formado por ambos archipiélagos, Asturias y Cantabria, cuyo peso relativo a escala nacional es residual. Castilla y León ocupa el sexto lugar, tras La Rioja, con un modesto $4 \%$, si se tiene presente la gran extensión de la región. Por provincias, cabe destacar la gran relevancia de Ciudad Real (con una producción de 10,7 millones de hectolitros en 2015, lo que representa el 24,7\% del total nacional), seguida de Toledo (11,75\%), Badajoz (9,3\%), Cuenca (8,8\%) y Albacete $(7,8 \%)^{2}$.

4) Una elevada atomización fabril. Con todo, cabe identificar, en medio de ese "minifundismo", un variado mosaico de situaciones en la estructura empresarial. Así, como apuntan Langreo y Castillo (2014), desde hace ya años, hay que contemplar el creciente papel de un cada vez más nutrido grupo de empresas de tamaño medio, que, junto a las de mayor envergadura, están detrás del fuerte impulso experimentado por el sector en los últimos años ${ }^{3}$.

${ }^{2}$ Las siguientes cinco provincias en el ranking de producción de 2015 son: Valencia (con 2,5 millones de hectolitros), La Rioja $(2,2)$, Barcelona $(2,0)$, Zaragoza $(1,3)$ y Tarragona $(1,1)$. Con casi 1 millón de hectolitros figura, en undécima posición, la provincia de Valladolid. Las cinco provincias con más baja producción son, de mayor a menor, Castellón, Jaén, Asturias, Palencia y Cantabria (cuyos 960 hectolitros constituyen la menor cifra del conjunto provincial).

${ }^{3}$ De acuerdo con Langreo y Castillo (2014), la actual estructura empresarial del sector -marcada por el crecimiento de inicios del presente siglo y por el posterior impacto de la crisis sobre el crédito y el consumo, además de por los ajustes inherentes a la última reforma de la OCM del vino (2009)-, la componen los siguientes grupos: a) Bodegas cooperativas de variable dimensión, la mayoría PYMES, destacando algunas grandes de primer y segundo grado en Castilla-La Mancha, Cataluña y otras regiones, que vienen registrando un aumento en su número de socios y su producción. Protagonizan la mayor parte de la elaboración de vino. b) El conjunto de empresas líderes del sector, encabezado por las firmas del cava (Freixenet y Codorníu), las de capital multinacional (Domecq y ARCO UW), González Byass (en Jerez), Miguel Torres, empresas de vinos económicos como Félix Solís y J. García Carrión, y grandes bodegas riojanas expandidas hacia otras DOP (Faustino, Vivanco, Barón de Ley, Marqués de Riscal,...) c) Un grupo intermedio eficaz y diversificado (con ventas entre 10 y 50 millones de euros) en el que se hallan algunos grandes exportadores (manchegos y valencianos, sobre todo), firmas de vinos económicos como Familia Huertas o López Morenas, Bodegas Ontañón (interproveedor de Mercadona) y otras bodegas de varias zonas con clara vinculación territorial; entre ellas figuran Paternina, Osborne, Chivite, Borsao, Arnoya,..., junto con algunas de la Ribera del Duero (Vega-Sicilia, Protos, Tinto Pesquera, Matarromera) y de Rueda (Agrícola Castellana). 
Figura 4

Distribución regional de la producción de vino en España, media 2000-2015 (\%)

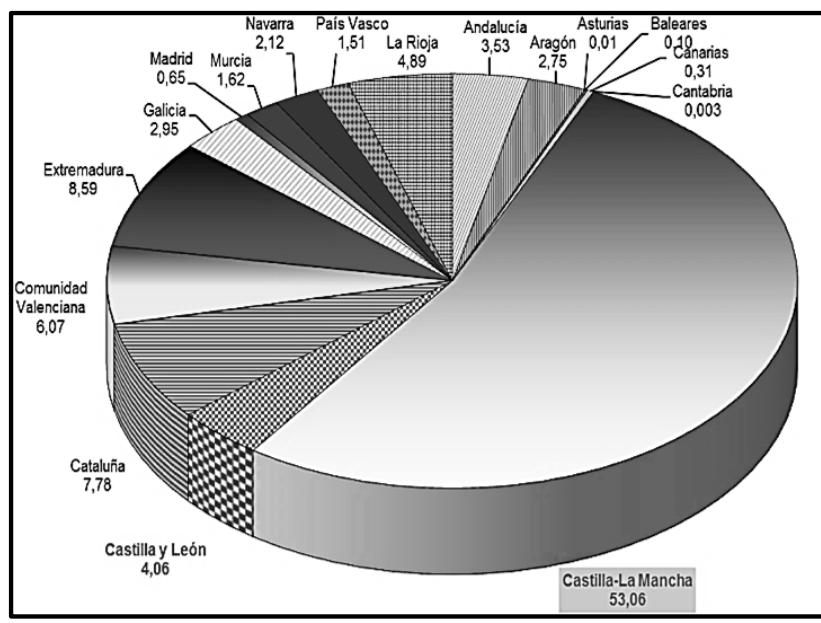

Fuente: Elaboración propia, a partir de los datos del Observatorio Español del Mercado del Vino.

5) El débil nivel de consumo interno. Tal debilidad, favorecida desde hace tiempo por el auge de la cerveza, se ha agudizado con la crisis y su impacto sobre el consumo realizado en el hogar y a través del canal HORECA (hostelería, restauración y catering); y todo apunta a la continuidad de su caída el lustro venidero, que Lago Moneo (2016) cifra en torno a un 15\%. De hecho, el gasto per cápita nacional (139 €, en 2015) es de por sí muy inferior al de productores tradicionales como Italia (el triple), Portugal (2,8 veces mayor) y Francia (362 €), e incluso del nuevo mundo, como Australia (253 €) y Nueva Zelanda (323 €).

6) La senda hacia mayores cotas de innovación y calidad, como respuesta al débil consumo interior, al contexto de crisis y a la cada vez mayor competencia a nivel global, no sólo de los tradicionales competidores franceses e italianos, sino también de otros más recientes, provenientes de Argentina, Chile, California, Sudáfrica, Australia o Nueva Zelanda. La incorporación de enólogos y personal cualificado en un creciente número de bodegas, la orientación de parte de la producción -y del marketing- hacia segmentos de población como jóvenes, mujeres y ancianos, el enoturismo, la creación de nuevos envases y formas de presentación, constituyen claros síntomas de una decidida apuesta en esta línea.

7) El creciente peso de los vinos con Denominación de Calidad, más resistentes a la caída en el consumo que los tradicionales vinos de mesa. Al albur de esa apuesta por la calidad, y con la implicación de las autoridades regionales y locales, en las últimas décadas ha aumentado notablemente el 
número de Denominaciones de Origen Protegidas (DOP) e Indicaciones Geográficas Protegidas (IGP); presentes en todas las CC.AA, constituyen manifestaciones de áreas de especialización productiva potencialmente configuradoras de SPLA. De hecho, el patrón de localización industrial, estrechamente ligado a la materia prima, y la vinculación territorial vía Denominaciones de Calidad, facultan la natalidad empresarial en áreas rurales, convirtiendo a la rama vinícola en factor de desarrollo local.

\subsection{El dinamismo exportador de la industria vinícola nacional}

Como ya se ha apuntado, España alcanzó, en 2015, el primer puesto en el ranking de países exportadores de vino, con unos 2.400 millones de litros, por delante de Italia y Francia, representando casi la cuarta parte de las exportaciones mundiales en volumen. Una proporción que contrasta con el más bajo porcentaje en términos de valor, 9,3\%, inherente al bajo precio medio de exportación del vino nacional -en torno a 1,10 euros por litro-, resultante del predominio de la venta al exterior de vino a granel (casi 1.300 millones de litros).

Figura 5

Evolución del comercio exterior de vino en España, 1999-2015

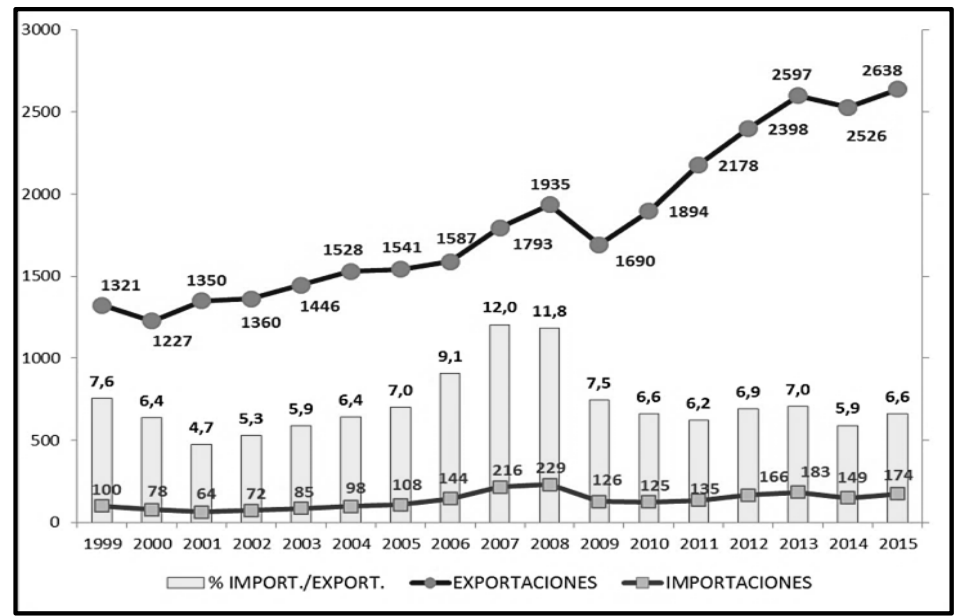

Fuente: Observatorio Español del Mercado del Vino.

No obstante, como se muestra en la Figura 5, entre 1999 y 2015, las exportaciones de vino se han duplicado en valor, pasando de 1.321 millones de euros a los actuales 2.638. La progresión exportadora es constante durante el periodo; aunque interrumpida en 2009 por la crisis, en 2010 retoma su senda ascendente hasta el máximo histórico actual. Las importaciones, aunque fueron en aumento hasta el bache de 2009, para después irse recuperando lentamente, alcanzan unos niveles muy bajos (174 millones de euros en 2015; sólo el 6,6\% 
del montante exportado); claro síntoma del gran peso del vino nacional en el consumo interno.

Conforme a los datos de la Figura 6, en 2015 el consumo nacional era tan sólo de 981 millones de litros, poco más de la mitad del nivel de hace 25 años (en 1991 se consumieron 1.716 millones, principalmente vía canal HORECA) y algo más de dos tercios del registrado a comienzos de siglo (1.424 millones, en 2001). Esta tendencia a la baja, presente también en productores tradicionales como Francia o Italia, contrasta con la creciente demanda de otros países como Japón, Canadá, los nórdicos (Suecia o Dinamarca), del este europeo (Rusia, Polonia o Hungría) y varios emergentes (China, Brasil, India, Sudáfrica o México), brindando oportunidades de exportación que contribuyan a compensar la caída del comercio interior agudizada por la recesión. En este sentido, desde 2004, el volumen de vino exportado supera al consumido en el país, ampliándose notablemente la brecha desde el inicio de la crisis. Los principales destinos del vino español son Francia, Alemania, Italia, Reino Unido y Portugal, lo que denota la importancia típica del factor proximidad, destacando en los últimos años el aumento de las ventas a Rusia (granel) y a China.

\section{Figura 6}

Evolución del consumo y de las exportaciones de vino en España, 1989-2015 (millones de litros)

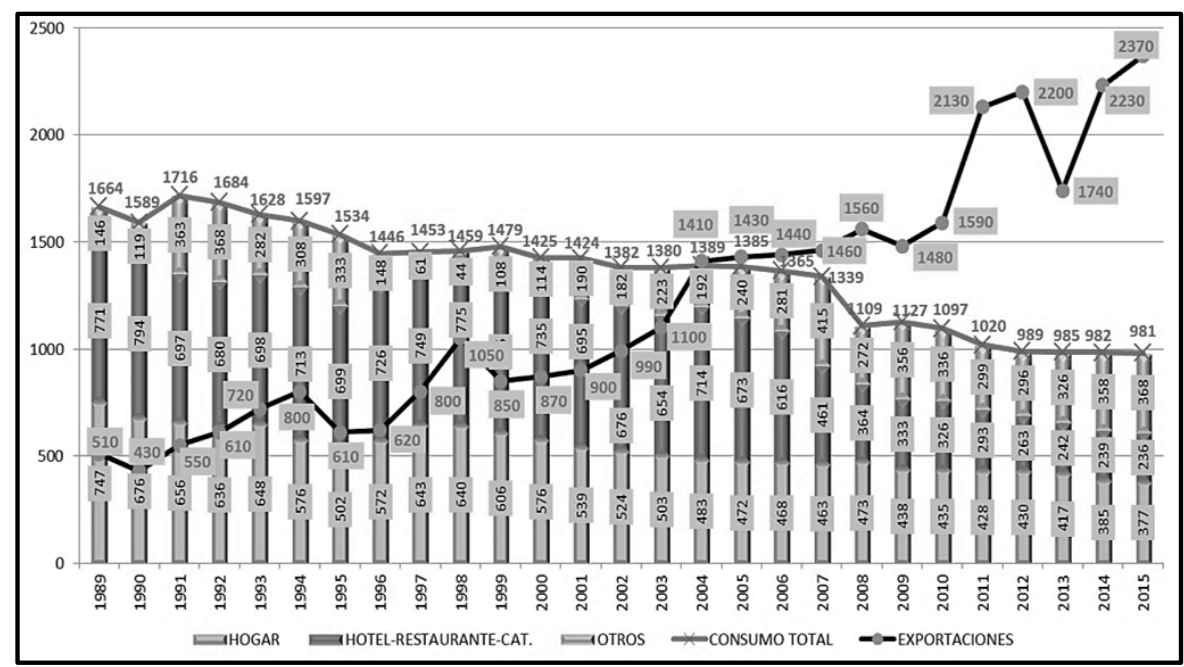

Fuente: Elaboración propia, a partir de los datos del Observatorio Español del Mercado del Vino.

Por regiones, la Tabla 3 recoge la evolución de las ventas al exterior en volumen (mosto incluido) de las diferentes Comunidades Autónomas, ordenadas de mayor a menor en función del dato correspondiente a 2015. Castilla-La Mancha figura en cabeza con el 44,3\% del total acumulado entre 2000 y 2015 
(sobre todo a granel), concentrando con las cuatro siguientes (Comunidad Valenciana, Extremadura, Cataluña y Murcia) el 81,7\% de las exportaciones del periodo. Las mayores tasas de crecimiento anual compuesto -que modera la volatilidad de las cifras registradas de un ejercicio a otro- se dan en Castilla-La Mancha, Murcia y Castilla y León (7,3\%), todas por encima de la media española $(6,9 \%)$.

\section{Tabla 3}

Evolución de las exportaciones de vino y mosto por regiones (miles de hectolitros)

\begin{tabular}{|c|c|c|c|c|c|c|c|c|c|c|c|c|c|c|c|c|c|c|}
\hline & 000 & 2001 & 002 & 2003 & 04 & 105 & 06 & 007 & 2008 & 2009 & 2010 & 011 & 012 & 013 & 2014 & 015 & & $\begin{array}{l}\% \\
\text { rCAC }\end{array}$ \\
\hline & 21,6 & 92,7 & $.0,1$ & 82,7 & 97,2 & 3,2 & 53,2 & 37,1 & $8.612,9$ & $7.499,6$ & $9.437,1$ & $|12.616,4|$ & $10.869,8$ & $9.680,0$ & $13.842,3$ & 320,0 & 4,2 & 11,4 \\
\hline & 76,6 & 36,5 & 02,6 & 30,3 & 65,0 & 87,4 & 73,1 & 34,7 & 38,6 & 53,7 & $1.793,9$ & 50,0 & 09,5 & $1.985,8$ & 27,7 & & 1,34 & 2,78 \\
\hline & 976,1 & $1.061,2$ & 792,0 & 800,5 & $1.131,7$ & $1.165,6$ & 529,9 & 3,1 & $1.181,3$ & $1.229,1$ & $1.738,0$ & 649,7 & 512,6 & $1.599,5$ & 497,9 & $.505,5$ & 7,84 & 3,4 \\
\hline & $1.475,1$ & $1.639,1$ & $1.670,5$ & $2.074,0$ & $2.118,1$ & $2.177,4$ & $2.002,2$ & $2.113,7$ & $2.269,2$ & $2.095,2$ & $2.187,8$ & $2.300,4$ & 330,7 & $2.269,7$ & $2.386,7$ & $2.419,3$ & 11,33 & 35 \\
\hline & 513,9 & 301,5 & 734,4 & 858,3 & 877,2 & $1.114,1$ & $1.267,8$ & $1.235,4$ & $1.383,6$ & $1.188,3$ & $1.759,6$ & 129,0 & 873,9 & $1.713,0$ & $1.684,9$ & $1.552,6$ & 6,92 & 7,65 \\
\hline & 471,6 & 634,7 & 702,0 & 659,3 & 697,1 & 833,9 & 900,0 & 910,1 & 936,6 & 833,3 & 899,1 & 944,8 & $1.042,2$ & $1.144,4$ & $1.168,3$ & $1.218,2$ & 4,73 & 6,53 \\
\hline & 281,2 & 316,6 & 324,2 & 387,7 & 478,7 & 584,9 & 516,1 & 534,6 & 545,5 & 472,9 & 427,9 & 552,1 & 560,9 & 602,0 & 21,4 & 89,4 & 2,60 & 5,0 \\
\hline & 1 & 0 & 279,9 & ,7 & 11 & 9,2 & & 2,2 & 5,5 & 349,7 & 376,4 & 0,2 &, 5 & 528,6 & 3,8 & 2,5 & 2,10 & 6,66 \\
\hline & 6 & 3 & 749,0 & 73 & 9 & 7,3 & 507,1 & 1,3 & 559,7 & 520,1 & 511,2 & 769,2 & 5,9 & 470,7 & 11,6 & 4,2 & 3,25 & $-2,35$ \\
\hline avarr & 75,1 & ,3 & 293,4 & 302,1 & 3,0 & 33,4 & 297,4 & 276,0 & 274,1 & 257,6 & 315,4 & 383,1 & 2,3 & 70,0 & 96,6 & 13,1 & , 79 & 2,7 \\
\hline Cast & 109,4 & 134,7 & 167,4 & 162,5 & 172,5 & 210,8 & \begin{tabular}{|l|}
238,6 \\
\end{tabular} & 245,1 & 271,8 & 269,4 & \begin{tabular}{|l|}
252,7 \\
\end{tabular} & 275,5 & \begin{tabular}{|l|}
326,8 \\
\end{tabular} & \begin{tabular}{|l|}
292,4 \\
\end{tabular} & 8,6 & 14,9 & 1,27 & 7,30 \\
\hline & 5,2 & & 87,0 & 135,4 & 243,2 & 1,1 & 9,6 & 59,8 & 11,8 & 289,0 & 16,0 & 32,8 & 15,9 & 283 & 0,5 & 64,2 & 1,52 & $-0,53$ \\
\hline & 135,5 & 51,0 & 194,7 & 194,1 & 201,3 & 190,0 & 128,0 & 125,5 & 135,7 & 86,0 & 155,9 & 189,5 & 152,6 & 190,5 & 07,3 & 210,8 & 0,90 & 2,99 \\
\hline & 13 & 0,5 & 0,8 & 1,6 & 0,9 & 0,7 & 1,7 & 2,3 & 2 & 3,5 & 4, & 4,2 & 4,4 & 6,4 & 7, & 8,6 & 0,02 & $-2,92$ \\
\hline & 61,1 & 40,9 & 3,6 & 2,8 & 0,1 & 0,3 & 3,5 & 3,8 & 1, & 2,2 & 3,1 & 3,7 & 4,4 & 3, & 4,4 & 4,3 & 0,05 & $-16,30$ \\
\hline & 2,4 & 5,8 & 3,0 & 1,2 & 1,5 & 1,5 & 3,0 & 6,0 & 8 & 8, & 8,2 & 9,9 & 6,4 & 6,0 & 5,0 & 3,3 & 0,03 & 2,2 \\
\hline & 0,3 & 0,1 & 0,0 & 0,2 & 0,0 & 0,1 & 1,9 & 0,0 & 0 & 1, & 1,8 & 0,3 & 0,1 & 0,6 & 0,5 & 0,0 & 0,00 & $-12,38$ \\
\hline & 4,6 & 2,9 & 3,8 & 5,2 & 3,5 & 4,5 & 21,9 & 1,7 & 2,8 & 2,3 & 6,6 & 23,6 & 20,5 & 18,8 & 32,6 & 15,6 & 0,06 & 8,52 \\
\hline TOTAL ESPAÑA & 0.176 & .657 & .798 & 14.513 & 16.594 & 16.245 & \begin{tabular}{|l|}
16.027 \\
\end{tabular} & \begin{tabular}{|l|}
17.812 \\
\end{tabular} & 18.912 & 16.862 & 20.095 & 25.894 & 3.815 & 21.165 & 6.737 & 7.629 & 100,00 & , 8 \\
\hline
\end{tabular}

Fuente: Observatorio Español del Mercado del Vino.

En términos de valor, la Tabla 4 ofrece análogamente un ranking regional liderado también en 2015 por Castilla-La Mancha, con más de 680 millones de euros. No obstante, tomando el periodo 2000-2015 en su conjunto, es Cataluña la región con mayor presencia internacional, al aglutinar casi la cuarta parte de las ventas de vino y mosto realizadas al exterior. Dentro del quinteto de cabeza, que concentra ahora el $61,1 \%$ (veinte puntos menos que en volumen) de los ingresos por exportación, aparecen La Rioja y País Vasco, a costa de Murcia y Extremadura.

También Castilla y León asciende en el ranking, pasando del undécimo lugar al séptimo, con un 4,5\% del total de ventas al exterior, frente al 1,3\% de la tabla anterior. No en vano, dicha región registra una tasa de crecimiento anual compuesto del 8,2\%, que, junto con las de Baleares, Asturias, Murcia y CastillaLa Mancha, rebasa ampliamente la media nacional (5,3\%). 
Tabla 4

Evolución de las exportaciones de vino y mosto por regiones (miles de euros)

\begin{tabular}{|c|c|c|c|c|c|c|c|c|c|}
\hline & 2000 & 2001 & 2002 & 2003 & 2004 & 2005 & 2006 & 2007 & 2008 \\
\hline Castilla-La Mancha & 204.669 & 212.247 & 226.270 & 283.975 & 341.381 & 297.194 & 326.327 & 386.339 & 462.828 \\
\hline Comunid. Valenciana & 135.580 & 134.887 & 124.969 & 158.315 & 149.433 & 129.799 & 124.068 & 148.028 & 153.609 \\
\hline Extremadura & 41.609 & 40.250 & 25.746 & 28.003 & 40.284 & 38.101 & 22.683 & 33.359 & 49.098 \\
\hline Cataluña & 359.125 & 416.705 & 389.769 & 409.122 & 424.529 & 455.039 & 447.398 & 543.021 & 610.147 \\
\hline Murcia & 39.555 & 41.967 & 50.262 & 58.109 & 62.496 & 77.507 & 86.680 & 92.048 & 102.286 \\
\hline La Rioja & 155.973 & 180.805 & 196.113 & 197.133 & 205.299 & 220.378 & 243.138 & 256.714 & 255.022 \\
\hline Aragón & 48.480 & 49.267 & 52.078 & 56.401 & 64.202 & 74.544 & 70.278 & 72.024 & 79.182 \\
\hline País Vasco & 88.734 & 100.611 & 103.254 & 100.330 & 96.483 & 103.787 & 120.105 & 147.249 & 124.707 \\
\hline Andalucía & 153.630 & 175.558 & 173.411 & 158.128 & 144.623 & 130.933 & 126.912 & 122.471 & 110.762 \\
\hline Navarra & 55.469 & 57.620 & 54.071 & 59.748 & 58.416 & 53.191 & 60.516 & 61.713 & 61.352 \\
\hline Castilla y León & 46.270 & 52.701 & 60.937 & 59.020 & 65.316 & 71.413 & 78.050 & 90.687 & 99.839 \\
\hline Galicia & 17.263 & 21.810 & 17.545 & 11.997 & 17.769 & 23.420 & 27.372 & 31.164 & 22.277 \\
\hline Madrid & 14.933 & 15.025 & 20.663 & 21.297 & 19.390 & 16.471 & 16.556 & 18.708 & 19.766 \\
\hline Baleares & 553 & 299 & 285 & 549 & 906 & 496 & 820 & 1.160 & 1.509 \\
\hline Canarias & 2.062 & 1.236 & 278 & 277 & 42 & 148 & 299 & 498 & 1.139 \\
\hline Asturias & 315 & 563 & 543 & 233 & 351 & 451 & 701 & 1.957 & 2.006 \\
\hline Cantabria & 34 & 414 & 65 & 228 & 14 & 39 & 96 & 18 & 46 \\
\hline Sin regionalizar & 2.093 & 979 & 1.077 & 1.880 & 1.730 & 2.123 & 3.346 & 420 & 993 \\
\hline TOTAL ESPAÑA & 1.366 .347 & 1.502 .943 & 1.497 .335 & 1.604 .744 & 1.692 .663 & 1.695 .033 & $\mid 1.755 .346$ & 2.007 .578 & 2.156.566 \\
\hline
\end{tabular}

\begin{tabular}{|c|c|c|c|c|c|c|c|c|c|}
\hline & 2009 & 2010 & 2011 & 2012 & 2013 & 2014 & 2015 & $\begin{array}{c}\% s / \Sigma \\
(00-15)\end{array}$ & $\begin{array}{c}\% \\
\text { TCAC }\end{array}$ \\
\hline Castilla-La Mancha & 370.541 & 430.180 & 586.727 & 662.110 & 739.483 & 686.968 & 682.207 & 20,75 & 8,36 \\
\hline Comunid. Valenciana & 130.313 & 138.868 & 174.022 & 212.092 & 222.366 & 215.907 & 224.919 & 7,75 & 3,43 \\
\hline Extremadura & 45.974 & 58.651 & 102.354 & 117.839 & 102.777 & 101.286 & 98.998 & 2,85 & 5,95 \\
\hline Cataluña & 488.803 & 532.817 & 554.305 & 608.199 & 648.577 & 603.083 & 648.028 & 24,48 & 4,01 \\
\hline Murcia & 103.690 & 128.202 & 164.949 & 189.706 & 193.622 & 193.805 & 175.710 & 5,30 & 10,45 \\
\hline La Rioja & 226.384 & 252.221 & 293.302 & 288.327 & 340.832 & 330.964 & 351.606 & 12,01 & 5,57 \\
\hline Aragón & 79.543 & 81.073 & 93.035 & 96.517 & 113.130 & 100.976 & 112.948 & 3,74 & 5,80 \\
\hline País Vasco & 121.038 & 129.022 & 150.304 & 160.211 & 181.131 & 196.258 & 203.477 & 6,40 & 5,69 \\
\hline Andalucía & 104.700 & 104.098 & 108.702 & 116.148 & 109.950 & 120.165 & 119.824 & 6,26 & $-1,64$ \\
\hline Navarra & 55.092 & 61.067 & 70.170 & 76.471 & 68.599 & 74.247 & 78.772 & 3,03 & 2,37 \\
\hline Castilla y León & 96.757 & 100.370 & 110.535 & 133.240 & 135.405 & 144.813 & 150.620 & 4,50 & 8,19 \\
\hline Galicia & 24.532 & 27.469 & 30.496 & 37.540 & 45.681 & 40.152 & 42.561 & 1,32 & 6,20 \\
\hline Madrid & 16.312 & 24.512 & 31.298 & 33.085 & 41.533 & 43.151 & 43.960 & 1,19 & 7,46 \\
\hline Baleares & 1.746 & 2.958 & 3.399 & 3.726 & 5.326 & 5.824 & 5.957 & 0,11 & 17,18 \\
\hline Canarias & 1.368 & 1.697 & 1.929 & 2.128 & 2.882 & 3.700 & 3.731 & 0,07 & 4,03 \\
\hline Asturias & 1.403 & 1.775 & 1.378 & 1.328 & 1.442 & 1.168 & 1.413 & 0,05 & 10,54 \\
\hline Cantabria & 247 & 227 & 194 & 112 & 95 & 108 & 15 & 0,01 & $-5,12$ \\
\hline Sin regionalizar & 729 & 2.080 & 9.273 & 9.124 & 7.716 & 10.500 & 9.023 & 0,19 & 10,23 \\
\hline TOTAL ESPAÑA & 1.869 .173 & 2.077 .286 & 2.486 .373 & 2.747 .902 & 2.960 .546 & 2.873 .076 & 2.953 .772 & 100,00 & 5,27 \\
\hline
\end{tabular}

Fuente: Observatorio Español del Mercado del Vino.

Profundizando en el análisis territorial, y dada la creciente importancia de las Denominaciones de Calidad ${ }^{4}$, en la Tabla 5 se ofrecen datos correspondientes a

\footnotetext{
${ }^{4}$ En la campaña 1982-83, había en España una superficie de viñedo inscrita para la producción de vinos VCPRD (vinos de calidad producidos en una región determinada) de 489.472 hectáreas (el 29,9\% de un total de 1.636.091). En 2000-2001, dicha superficie había aumentado a 641.617 (el 54,9\% de un total de 1.167.700), distribuidas entre 56 DOP. En la campaña 2014-2015 han sido 574.038 hectáreas, una superficie menor, repartida entre un mayor número de DOP -resultante en buena parte de años de arranque masivo de viñedo- pero que alcanza ya el $61,7 \%$ del total.
} 
las 20 mayores DOP (de las 90 existentes) por cantidad de hectáreas cultivadas, las cuales suponen el 96,7\% de la extensión dedicada al viñedo DOP, el 72\% del número de viticultores, el 68,5\% del número de bodegas y más del $80 \%$ del comercio total de vinos DOP, tanto en volumen como en términos de valor.

Tabla 5

Principales indicadores de las 20 mayores DOP por superficie de viñedo, 2015

\begin{tabular}{|c|c|c|c|c|c|c|c|c|c|}
\hline 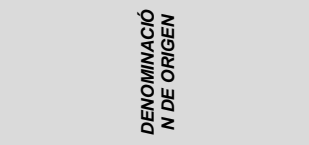 & 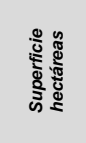 & 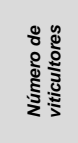 & 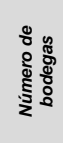 &  & 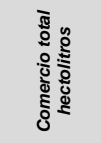 & 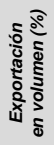 & 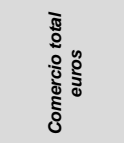 & 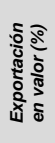 &  \\
\hline LA MANCHA & 163.167 & 15.802 & 252 & 680.270 & 509.593 & 29,4 & 156.336 .509 & 19,7 & 3,1 \\
\hline RIOJA & 64.539 & 16.035 & 797 & 2.947 .913 & 2.803 .147 & 38,2 & 456.231 .568 & n.d. & 1,6 \\
\hline CATALUÑA & 43.655 & 6.127 & 211 & 480.102 & 476.633 & 50,3 & 143.958 .675 & 50,8 & 3,0 \\
\hline UTIEL-REQUENA & 33.658 & 5.652 & 96 & 270.543 & 179.812 & 74,7 & 53.615 .755 & 74,3 & 3,0 \\
\hline CAVA & 33.325 & 6.350 & 402 & 1.908 .965 & 1.816 .598 & 63,0 & 721.770 .762 & 47,8 & 4,0 \\
\hline RIBERA DEL GUADIANA & 33.281 & 3.124 & 21 & 62.906 & 28.758 & 5,9 & 7.402 .820 & 8,6 & 2,6 \\
\hline VALDEPEÑAS & 22.461 & 2.559 & 34 & 415.646 & 572.851 & 38,4 & 113.549 .242 & 39,7 & 2,0 \\
\hline RIBERA DEL DUERO & 21.964 & 8.254 & 307 & 827.615 & 671.579 & 12,5 & 364.895 .424 & 19,5 & 5,4 \\
\hline JUMILLA & 21.620 & 1.959 & 43 & 390.354 & 218.080 & 49,5 & 46.454 .779 & 46,6 & 2,1 \\
\hline PENEDÉS & 17.894 & 2.815 & 178 & 143.173 & 131.782 & 30,6 & 87.152 .593 & 35,2 & 6,6 \\
\hline CARIÑENA & 14.459 & 1.587 & 34 & 568.765 & 375.547 & 70,6 & 62.692 .195 & 74,3 & 1,7 \\
\hline VALENCIA & 13.080 & 6.150 & 93 & 338.258 & 485.152 & 69,8 & - & n.d. & - \\
\hline RUEDA & 12.995 & 1.516 & 69 & 610.800 & 709.302 & 12,1 & 177.325 .315 & 12,1 & 2,5 \\
\hline NAVARRA & 11.025 & 2.372 & 104 & 480.999 & 375.926 & 37,1 & 72.060 .000 & 42,6 & 1,9 \\
\hline ALICANTE & 9.986 & 1.645 & 45 & 109.629 & 134.333 & 22,9 & - & n.d. & - \\
\hline RIBERA DEL JÚCAR & 9.050 & 895 & 10 & 38.178 & 3.607 & 42,3 & 1.009 .764 & 52,6 & 2,8 \\
\hline VINOS DE MADRID & 8.391 & 2.890 & 46 & 24.585 & 24.586 & 29,3 & 1.957 .466 & n.d. & 0,8 \\
\hline ALMANSA & 7.200 & 760 & 12 & 38.178 & 44.919 & 68,0 & 9.543 .509 & 78,4 & 2,1 \\
\hline CAMPO DE BORJA & 6.809 & 1.151 & 18 & 180.051 & 135.877 & 59,0 & 33.039 .708 & 61,4 & 2,4 \\
\hline JEREZ-MANZANILLA SANLÚCAR & 6.715 & 1.764 & 91 & 446.775 & 362.220 & 66,8 & 108.664 .953 & 66,8 & 3,0 \\
\hline TOTAL 20 PRIMERAS & 555.274 & 89.407 & 2.863 & 10.963 .705 & 10.060 .302 & 43,9 & 2.617 .661 .037 & - & - \\
\hline TOTAL ESPAÑA & 574.038 & 123.617 & 4.120 & 12.426 .827 & 11.582 .429 & 41,3 & 3.206.741.119 & - & - \\
\hline 20 PRIMERAS I TOTAL ESPAÑA (\%) & 96,73 & 72,33 & 69,49 & 88,23 & 86,86 & & 81,63 & & \\
\hline
\end{tabular}

Fuente: Elaboración propia, a partir de los datos del MAGRAMA.

Sobresale por su dimensión geográfica la DOP La Mancha, con un 28,4\% de la superficie de referencia, que alcanza el $35,2 \%$ si se incorporan las otras manchegas de la muestra: Valdepeñas, Ribera del Júcar y Almansa. La Rioja prevalece en número de viticultores y de bodegas, volumen de vino calificado y comercio en volumen, seguida de los productores de cava, que lideran el comercio total en valor, y de la Ribera del Duero.

En 2015 se han exportado 4.779.090 hectolitros, un 4,85\% menos que durante el año anterior ${ }^{5}$. Con todo, dicha cifra resulta muy superior a las registradas a comienzos de siglo (3.692.890 hectolitros en 2001) e incluso con anterioridad a la

${ }^{5}$ A falta de datos sobre exportaciones para DOP menores, como Alella, Granada y Valtiendas. Para el comercio en valor hay más lagunas, al carecer de datos para DOP relevantes como Valencia, Alicante o Rioja (comercio interior). 
crisis (4.678.844 en 2007), que apenas se ha dejado sentir en la comercialización exterior de este tipo de vinos (en 2009 se vendieron 4.412.228), con una tasa de crecimiento anual compuesto del 1,73\%. En tal dinámica influye la resistencia del vino a granel, atractivo por su bajo precio para un importante segmento de consumidores foráneos y para numerosas bodegas extranjeras que los utilizan para enriquecer sus vinos.

El mayor grado de internacionalización lo presentan la DOP de Jerez (sin la DOP Manzanilla de Sanlúcar, con la que comparte superficie) y la de UtielRequena, ambas con más del 75\% de sus ventas en volumen destinado al exterior; les siguen Valencia, Cariñena y Almansa, con más de dos tercios. En términos de valor, Almansa y Cariñena se suman al dúo anterior, destacando asimismo Campo de Borja; todas superan con creces la media nacional (41,3\%). Con todo, las exportaciones más cuantiosas corresponden a la DOP plurirregional del Cava (con el 23,9\% del volumen total de vino DOP exportado) y Rioja $(22,4 \%)$, seguidas a mucha distancia de Valencia, Cariñena, Jerez-Manzanilla de Sanlúcar (5,1\%) y Cataluña.

Las dos mayores DOP de Castilla y León, Ribera del Duero y Rueda, presentan (junto con Ribera del Guadiana) el más bajo peso de las exportaciones en sus ventas, con porcentajes muy similares en volumen, pero no así en valor, donde el 19,5\% de Ribera del Duero resulta del elevado precio medio de sus vinos (5,4 euros por litro, el mayor de la muestra tras el Penedés). En dicho precio influyen las altas restricciones del Consejo Regulador en cuanto a rendimientos por hectárea (4.100 en promedio), que implican labores de poda y selección de la uva más intensas, y el marcado sesgo hacia crianzas y reservas. En todo caso, el peso de ambas zonas en la exportación nacional de vino DOP es muy reducido (1,76\% y $1,80 \%$, respectivamente, en volumen, y 4,87\% y $1,47 \%$, en valor).

Los principales países compradores del vino español con DOP $\operatorname{son}^{6}$ : Reino Unido (21,2\% de la exportación total en 2015), Alemania (17,1\%), EE.UU. (9,6\%), Bélgica (7,2\%), Holanda (5,7\%), China (4,3\%), Suiza (3,9\%), Francia (3,6\%), Japón (3,18\%) y Canadá (3,16\%). La composición de estos 10 primeros destinos es la misma desde 2012, con EE.UU, Bélgica y China ganando peso, frente a Francia, Suiza y Holanda, y con Reino Unido líder a costa de Alemania. Los dos asiáticos y Canadá han desplazado de la lista a Suecia y Dinamarca. En

\footnotetext{
${ }^{6}$ En cuanto a los tipos de vino DOP exportado, se viene dando desde hace muchos años el mismo orden, con un claro predominio del tinto, que en la campaña 2014-2015 ha supuesto el 54,9\% del volumen total. Le siguen el vino espumoso $(24,1 \%)$-que también ha ido ganando terreno- y el blanco (11,5\%); a mucha distancia figuran el vino de licor $(5,6 \%)$ y el rosado $(3,7 \%)$. Por tipos de envase, hay una abrumadora y creciente superioridad del vino embotellado (el 96,5\% del total) frente al vino DOP exportado a granel (actualmente con un exiguo 3,5\%, cuando en 2001 alcanzaba el 17,9\%). El Rioja es dominante en Reino Unido, Suecia, Suiza, Canadá y Rusia; el Cava destaca en Alemania, Bélgica, Francia, EE.UU. y Japón; el vino de Valencia en China y el Jerez-Xérès-Sherry en Holanda.
} 
los últimos años se detecta una paulatina diversificación geográfica: si en 2015 dos tercios de las exportaciones han ido a la Unión Europea, esa cifra era del 75\% en 2009, al inicio de la crisis; América Latina, Asia Oriental y, en menor medida, África han ido adquiriendo importancia. Un aspecto digno de análisis futuro en medio de este proceso de mayor internacionalización, es el impacto inherente al apoyo de los poderes públicos, del ICEX y los Consejos Reguladores.

Análogamente, la Tabla 6 recoge los datos referidos a las 20 principales Indicaciones Geográficas Protegidas (de un total de 41), que totalizan el 99,5\% de la superficie de viñedo amparada por dicha figura, el $97 \%$ de los viticultores, el $91,2 \%$ de las bodegas y más del $98,6 \%$ del comercio total en volumen y en valor (que asciende a más del 99\% en el caso del comercio exterior). De nuevo Castilla-La Mancha aparece en primer lugar, merced al peso de la IGP Vinos de la Tierra de Castilla. Las IGP de Castilla y León, Extremadura, Bajo Aragón y Cádiz completan el quinteto principal en las diferentes variables recogidas, seguidas de Mallorca, con un importante número de bodegas y un alto montante comercializado en valor, resultante de su elevado precio medio por litro (6,72 euros, el más elevado de la muestra, tras los 7,43 de Ibiza).

Tabla 6

Principales indicadores de las 20 mayores IGP por superficie de viñedo, 2015

\begin{tabular}{|c|c|c|c|c|c|c|c|c|c|}
\hline $\begin{array}{c}\text { INDICACIÓN GEOGRÁFICA } \\
\text { PROTEGIDA }\end{array}$ & $\begin{array}{l}\text { Superficie } \\
\text { hectáreas }\end{array}$ & $\begin{array}{l}\text { Número de } \\
\text { viticultores }\end{array}$ & $\begin{array}{c}\text { Número } \\
\text { de } \\
\text { bodegas }\end{array}$ & $\begin{array}{c}\text { Volumen de } \\
\text { vino } \\
\text { calificado }\end{array}$ & $\begin{array}{c}\text { Comercio } \\
\text { total } \\
\text { hectolitros }\end{array}$ & $\begin{array}{c}\text { Exportación } \\
\text { en volumen } \\
(\%)\end{array}$ & $\begin{array}{c}\text { Comercio } \\
\text { total } \\
\text { euros }\end{array}$ & $\left|\begin{array}{l}\text { Exportación } \\
\text { en valor }(\%)\end{array}\right|$ & $\begin{array}{l}\text { Precio } \\
\text { medio } \\
€ / \text { litro }\end{array}$ \\
\hline CASTILLA & 58.977 & 5.939 & 224 & 1.844 .994 & 1.428 .702 & 24,76 & 118.463 .773 & 40,52 & 0,83 \\
\hline CASTILLA Y LEÓN & - & - & 168 & 173.101 & 157.940 & 34,86 & 31.588 .024 & 34,86 & 2,00 \\
\hline EXTREMADURA & 9.012 & 1.907 & 86 & 535.448 & 245.747 & 24,23 & 16.232 .773 & 25,49 & 0,66 \\
\hline BAJO ARAGÓN & 1.09 & 194 & 14 & 25.903 & 18.643 & 9,12 & 2.628 .441 & 15,45 & 1,41 \\
\hline CÁDIZ & 1.007 & 642 & 18 & 50.389 & 45.176 & 10,34 & 13.572 .994 & 12,12 & 3,00 \\
\hline MALLORCA & 573 & 188 & 43 & 17.782 & 18.255 & 34,16 & 12.262 .681 & 35,00 & 6,72 \\
\hline MURCIA & 448 & 38 & 3 & 595 & 13.012 & 98,32 & 1.817.989 & 98,07 & 1,40 \\
\hline VALLE DEL CINCA & 440 & 6 & 2 & 22.950 & 10.978 & 96,14 & 2.449 .127 & 96,15 & 2,23 \\
\hline RIBERA DEL JILOCA & 300 & 107 & 2 & 5.129 & 6.221 & 1,49 & 412.500 & 14,18 & 0,66 \\
\hline LAUJAR-ALPUJARRA & 242 & 45 & 6 & 1.866 & 3.067 & 1,08 & 811.857 & 1,81 & 2,65 \\
\hline RIBERA GÁLLEGO-CINCO VILLAS & 192 & 45 & 5 & 5.070 & 4.295 & 11,59 & 794.053 & 20,54 & 1,85 \\
\hline CASTELLÓ & 166 & 99 & 12 & 3.622 & 3.832 & 3,68 & 788.450 & 7,28 & 2,06 \\
\hline VALDEJALÓN & 137 & 1 & 1 & 1.568 & 319 & 28,21 & 52.348 & 76,78 & 1,64 \\
\hline VALLES DE SADACIA & 129 & 9 & 2 & 2.015 & 1.113 & 27,04 & 348.460 & 25,89 & 3,13 \\
\hline ALTIPLANO DE SIERRA NEVADA & 123 & 17 & 10 & 2.140 & 1.158 & 0,43 & 409.730 & 0,91 & 3,54 \\
\hline CÓRDOBA & 77 & 43 & 6 & 6.544 & 1.411 & 6,24 & 273.453 & 10,57 & 1,94 \\
\hline RIBERA DEL QUEILES & 71 & 2 & 3 & 2.958 & 772 & - & 187.067 & - & 2,42 \\
\hline LADERAS DEL GENIL & 69 & 18 & 4 & 1.236 & 972 & 6,28 & 476.391 & 6,27 & 4,90 \\
\hline CUMBRES DEL GUADALFEO & 65 & 16 & 5 & 3.009 & 364 & 5,49 & 81.483 & 12,27 & 2,24 \\
\hline IBIZA & 58 & 28 & 5 & 1.457 & 1.164 & 13,06 & 864.574 & 13,06 & 7,43 \\
\hline TOTAL 20 PRIMERAS & 73.183 & 9.344 & 619 & 2.707 .776 & 1.963 .141 & 25,76 & 204.516 .168 & 36,30 & 1,04 \\
\hline TOTAL ESPAÑA & 73.528 & 9.630 & 679 & 2.719 .594 & 1.973 .037 & 25,71 & 207.447 .565 & 35,93 & 1,05 \\
\hline 20 PRIMERAS I TOTAL ESPAÑA (\%) & 99,53 & 97,03 & 91,16 & 99,57 & 99,50 & & 98,59 & & \\
\hline
\end{tabular}

Fuente: Elaboración propia, a partir de los datos del MAGRAMA.

Respecto a las exportaciones, a nivel intraterritorial, Murcia y Valle de Cinca 
muestran la mayor proyección internacional: casi todas sus ventas en volumen y en valor van destinadas al exterior. Les siguen Mallorca y Castilla y León -con algo más de un tercio en ambos casos-, y Extremadura, Valles de Sadacia, Castilla y Valdejalón, con cerca de una cuarta parte (siendo el porcentaje en valor mucho mayor en estos dos últimos territorios). A escala interterritorial, la manchega IGP Castilla es, con diferencia, la de mayor entidad, con una participación en las exportaciones nacionales de este tipo de vinos del $64,4 \%$ en valor y del 69,7\% en volumen; a mucha distancia figuran Castilla y León (14,8\% y 10,8\%), Extremadura y Mallorca; esta última e Ibiza registran el mayor precio por litro exportado (en torno a 7 euros), lo que no es ajeno a su carácter insular.

La evolución de las exportaciones, a la luz de los datos del MAGRAMA, resulta favorable: si bien en 2015 se constata una caída en volumen del 14,8\% respecto a 2014 (507.195 hectolitros frente a 595.399), no ocurre lo mismo en valor (los 74,5 millones de euros de 2015 suponen un aumento del 6,6\% respecto al año anterior y un máximo histórico). Además, dicho montante en volumen resulta muy superior al de los años anteriores, con una tasa de crecimiento anual compuesto del 7\% desde la campaña 2008-2009. Los principales destinos de los vinos con IGP son: Alemania (21,2\% del total exportado en 2015), China $(11,4 \%)$, Francia (8,6\%), Portugal (7,0\%) y Polonia (6,5\%), seguidos de EE.UU., Italia, Reino Unido, Rusia, Suecia y Holanda.

\section{LA INDUSTRIA DEL VINO EN CASTILLA Y LEÓN}

Siguiendo el hilo argumental utilizado para España, a continuación se analiza el peso de la rama vitivinícola dentro de la IAA de Castilla y León y se identifican algunos de sus principales rasgos, para después hacer referencia al ámbito de las exportaciones.

\subsection{La industria del vino en el contexto de la IAA regional}

La alta concentración sectorial propia de la IAA nacional, se reproduce en su homónima castellana y leonesa con más intensidad. Así, aunque la IAA regional ofrece una muy variada gama de productos, destacan particularmente tres ramas (Tabla 7): Industrias cárnicas; Pan, bollería, pastelería y galletas e Industrias lácteas. En 2014, este trío aglutina el 66\% de las empresas, el 63,2\% del empleo y el 54,8\% de la facturación del sector. Les siguen en importancia Productos de alimentación animal y Vinos ${ }^{7}$.

\footnotetext{
${ }^{7}$ Aparte de la fuerte concentración sectorial, otros rasgos de la IAA castellana y leonesa son: a) La entrada masiva de capital de grandes multinacionales. Ese capital foráneo suele ubicar sus fábricas en núcleos urbanos de la región con sólidas infraestructuras de transporte y comunicaciones, y sus sedes sociales en grandes centros de decisión, como Barcelona y Madrid; su presencia no es ajena a los avances en tecnología y productividad (inducidos por la innovación y el ajuste de plantillas) ni a la terciarización (animada por la gran distribución), experimentados por el sector. b) La
} 
Las 555 empresas vinícolas de la región dan empleo a unos 3.700 trabajadores, con un volumen de ventas netas de 612 millones de euros; tales cifras suponen, con relación a la IAA regional, el $18,4 \%$, el $10,5 \%$ y el $6,5 \%$ del total, respectivamente. En relación con su peso dentro de la industria nacional del vino, los porcentajes respectivos son $13,7 \%, 14,9 \%$ y $10,5 \%$.

Tabla 7

Principales indicadores de la IAA de Castilla y León, por ramas, 2014

\begin{tabular}{|c|c|c|c|c|c|c|c|c|c|}
\hline SUBSECTOR & $\begin{array}{l}\text { Número } \\
\text { de } \\
\text { Empresas }\end{array}$ & Empleo & $\begin{array}{l}\text { Ventas netas } \\
\text { de Producto } \\
\text { (millones } € \text { ) }\end{array}$ & $\begin{array}{l}\text { Consumo } \\
\text { Materias } \\
\text { primas } \\
\text { (millones } € \text { ) }\end{array}$ & $\begin{array}{c}\text { Inversión } \\
\text { Activos Mat. } \\
\text { (millones } € \text { ) }\end{array}$ & $\begin{array}{c}\text { Coste Laboral } \\
\text { por empleado } \\
\text { (euros) }\end{array}$ & $\begin{array}{c}\text { Valor } \\
\text { Añadido } \\
\text { por } \\
\text { empleado } \\
\text { (miles } € \text { ) }\end{array}$ & $\begin{array}{c}\text { Ventas } \\
\text { netas } \\
\text { por } \\
\text { empleado } \\
\text { (miles } € \text { ) }\end{array}$ & $\begin{array}{c}\text { Tamaño } \\
\text { Medio de } \\
\text { Empresas }\end{array}$ \\
\hline Industrias cárnicas & 793 & 10.646 & 2.604 & 1.816 & 45,3 & 27.740 & 46 & 245,0 & 13,4 \\
\hline Transformación de pescado & 14 & 480 & 170 & 130 & 4,8 & 30.667 & 59 & 354,0 & 34,3 \\
\hline Conservas de frutas y hortalizas & 82 & 2.414 & 421 & 221 & 16,0 & 30.530 & 50 & 174,0 & 29,4 \\
\hline Grasas y aceites & 22 & 193 & 39 & 26 & 1,6 & 25.000 & 25 & 204,0 & 8,8 \\
\hline Industrias lácteas & 160 & 4.260 & 1.442 & 835 & 19,0 & 37.995 & 61 & 339,0 & 26,6 \\
\hline Productos de molinería & 70 & 515 & 292 & 245 & 5,7 & 33.816 & 61 & 566,0 & 7,4 \\
\hline $\begin{array}{l}\text { Pan, pastelería, pastas } \\
\text { alimenticias }\end{array}$ & 1.044 & 7.320 & 1.088 & 352 & 68,2 & 24.689 & 46 & 149,0 & 7,0 \\
\hline Azúcar, chocolate y confitería & 55 & 1.332 & 591 & 323 & 26,3 & 53.225 & 78 & 444,0 & 24,2 \\
\hline Otros productos diversos & 66 & 2.163 & 614 & 208 & 32,0 & 39.334 & 160 & 284,0 & 32,8 \\
\hline $\begin{array}{l}\text { Productos de alimentación } \\
\text { animal }\end{array}$ & 96 & 1.773 & 1.348 & 1.036 & 24,0 & 36.931 & 86 & 790,0 & 18,5 \\
\hline Vinos & 555 & 3.695 & 612 & 180 & 53,3 & 30.428 & 74 & 166,0 & 6,7 \\
\hline Otras bebidas alcohólicas & 46 & 176 & 70 & 22 & 1,1 & 56.955 & 199 & 406,0 & 3,8 \\
\hline Aguas y bebidas alcohólicas & 21 & 287 & 66 & 21 & $(-5,7)$ & 33.672 & 72 & 229,0 & 13,7 \\
\hline Otros (Sin sectorializar) & - & 275 & 13 & 5 & 1,6 & - & - & - & - \\
\hline TOTAL IAA CASTILLA Y LEÓN & 3.024 & 35.529 & 9.370 & 5.420 & 298,9 & 30.702 & 62 & 264,0 & 11,7 \\
\hline $\begin{array}{l}\text { TOTAL INDUSTRIA CASTILLA } \\
\text { Y LEÓN }\end{array}$ & 11.844 & 119.752 & 30.237 & 17.418 & $1.035,0$ & 34.538 & 68 & 253,0 & 10,1 \\
\hline
\end{tabular}

Fuente: Elaboración propia, a partir de INE: Encuesta Industrial de Empresas.

El tamaño empresarial medio, aunque algo superior a la media nacional, es también muy modesto (6,7 empleados); el más bajo de la IAA castellana y leonesa tras la rama Otras bebidas alcohólicas, y muy inferior a promedios de la IAA $(11,7)$ y del conjunto de la industria de la región $(10,1)$. El volumen de ventas por empleado (166.000 €) es asimismo reducido, en comparación con la gran mayoría de las ramas agroalimentarias y con su equivalente nacional (235.000 €). No obstante, la productividad (74.000 € por empleado) supera la media de la IAA (62.000) y de la industria (68.000) regionales, así como la registrada por la industria española del vino (67.500). Ello, junto con un más bajo coste laboral por empleado respecto al subsector nacional y a la mayoría de las

progresiva internacionalización comercial, impulsada desde el ingreso en la UE y acelerada desde los años 90, convirtiendo a la IAA en una de las actividades de la región con mayores exportaciones, tras la automoción. c) Una relativa polarización a escala provincial, con Burgos y Valladolid a la cabeza en empleo y producción, seguidas de Salamanca y León, que destacan en número de establecimientos. No obstante esa concentración, el sector se ajusta a un modelo de localización territorial esencialmente disperso -comparado con la IAA española y con los ámbitos industriales regional y nacional-, que lo convierte en potencial factor de desarrollo rural. 
ramas de la IAA regional, se traduce en un reducido coste laboral unitario (CLU=0,41 € por empleado), igualmente algo inferior al de la actividad vinícola española y al de casi todas las ramas recogidas en la Tabla 7, a excepción de Otros productos diversos $(0,25)$ y Otras bebidas alcohólicas $(0,29)$.

\subsection{Caracterización general de la industria regional del vino}

En el caso de la industria vitivinícola de Castilla y León, cabe apuntar como rasgos fundamentales, esencialmente coincidentes con el caso español (aunque con algunas particularidades dignas de mención), los siguientes:

1) Una importante extensión geográfica. Según el Anuario de Estadística Agraria del MAGRAMA, en el año 2014 la región ha dedicado 74.718 hectáreas (el 8,03\% de la superficie vitícola nacional) a la producción de uva para vinificación, estando el $96 \%$ en régimen de secano. Sólo dos regiones, Castilla-La Mancha y Extremadura presentan una amplitud superior. Las áreas más extensas se hallan en las provincias de Valladolid (22.595 hectáreas) y Burgos (16.812), que concentran el 52,7\% de la superficie regional total. Les siguen, a distancia, Zamora (12.655) y León (11.882), siendo Palencia la provincia con menor presencia de viñedo en su campiña, con tan sólo 548 hectáreas (en el sur y sureste, básicamente) ${ }^{8}$.

2) Una producción en aumento. Ya se ha comentado que la producción vinícola en Castilla y León representa aproximadamente el 4\% del total nacional, tomando como base la producción conjunta (mosto incluido) del periodo 2000-2015. No obstante, desde una perspectiva de más largo plazo, remontando el análisis a niveles de hace 30 años, la Figura 7 refleja un perfil evolutivo general ascendente, más marcado que a escala nacional, aunque no tan intenso como en el País Vasco, Navarra y, sobre todo, La Rioja. Así, si en 1987 la producción de la región (1,3 millones de hectolitros) suponía tan sólo el 3,3\% de la española, en 2015 (1,8 millones) el porcentaje es del 4,3\%, con máximos en 2012 (5,3\%) y 2014 (5,1\%). Aunque oscilante por añadas, como ya se ha señalado, dicha producción viene mostrando una trayectoria más regular que en otras regiones.

3) Una fuerte polarización territorial de la producción. A semejanza del caso español, el examen a escala provincial permite constatar, en correlación con la superficie cultivada, una gran concentración de la producción en Valladolid (1,07 millones de hectolitros en 2014, el 61\% vino blanco) y Burgos (0,65 millones, el 99,7\% tinto y rosado); ambas reúnen conjuntamente el $75 \%$ de la producción total, lo que supone un más alto

${ }^{8}$ Dada la gran extensión de Castilla y León, el cultivo de viñedo sólo representa el 0,8\% de la superficie total regional, y el 2,1\% de las tierras de labranza (donde predominan los cereales), en contraste con el caso manchego (5,5\% y 12,2\%, respectivamente), vasco ( $2 \%$ y $17,2 \%$ ) y, sobre todo, riojano (9,1\% y 29,3\%). 
rendimiento global por hectárea en comparación con el resto. Zamora ( 0,24 millones) y León ( 0,18 millones) ocupan el tercer y cuarto puesto, respectivamente. Los niveles de producción más bajos se dan en Salamanca (9.377 hectolitros) y Palencia (12.656).

Figura 7

Evolución de la producción vinícola en las principales regiones (1987-2015)

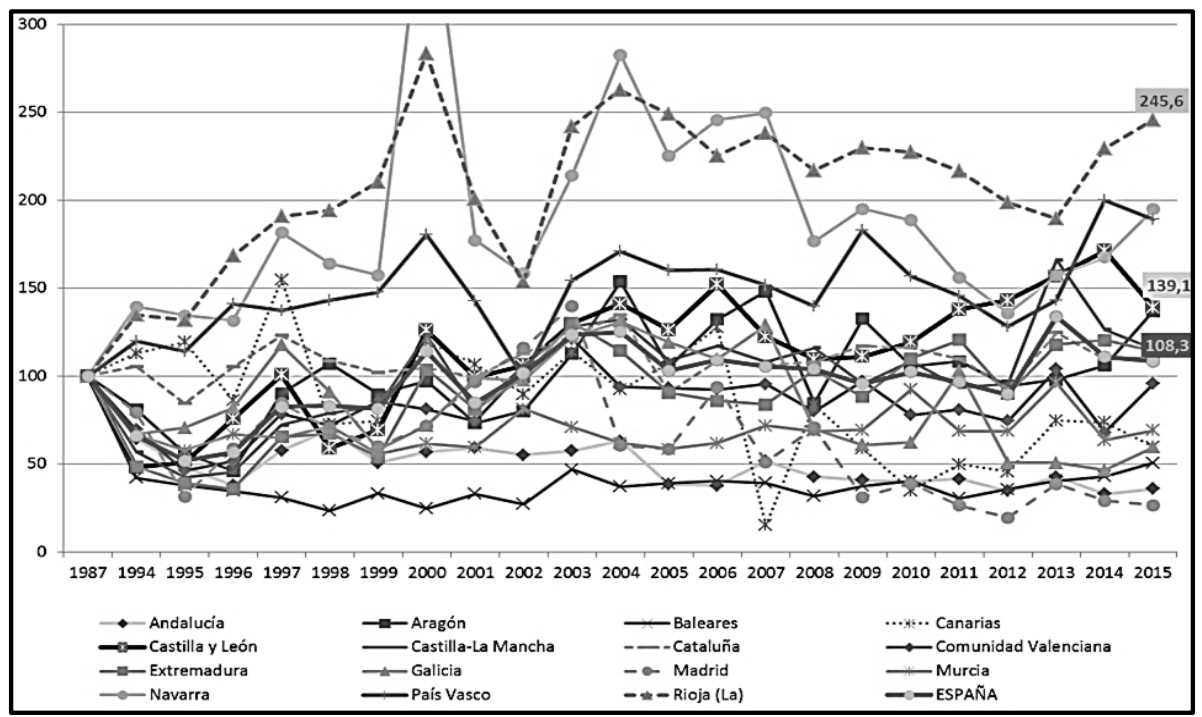

Fuente: Elaboración propia, a partir de los datos del Observatorio Español del Mercado del Vino.

4) Un reducido nivel de consumo. Lago Moneo (2016) estima el consumo de vino en Castilla y León durante el año 2015 en 15,65 litros por habitante y año, frente a los 18,99 de 2010; cifras, ambas, muy por debajo de las relativas a España (17,25 y 20,98 respectivamente). El nivel de gasto per cápita en vino en la región es de 126,26 € (en 2010 era de 147,17 €), netamente inferior a los $139,11 €$ vigentes a escala nacional (23,5 $€$ menos que en 2010) ${ }^{9}$.

5) El predominio de la empresa de pequeña dimensión, a menudo de carácter familiar. Ya se ha dicho que el tamaño medio de la empresa vinícola en la región, 6,7 trabajadores, aunque ligeramente superior a la media nacional,

\footnotetext{
${ }^{9}$ Lago Moneo (2016) señala una caída del consumo del 17,7\% para Castilla y León, en litros por habitante y año entre 2015 y 2019; para España contempla una caída del 14,7\%. Con arreglo a esas previsiones, el gasto por habitante en euros disminuiría un 15,4\% en España y un 18,4\% en la región, hasta llegar a un nivel de $103 €$ por persona. En todo caso, el nivel actual de consumo en la región resulta claramente inferior al de las regiones de mayor gasto per cápita en vino (Baleares, con 153,8 € y 19,1 litros, Cataluña, con 152,7 € y 18,9 litros, y la Comunidad Valenciana, con $149,5 €$ y 18,5 litros).
} 
es muy reducido, lo que, a priori, constituye una debilidad del sector, agudizada por el envejecimiento de los viticultores, especialmente en las cooperativas, en muchas de las cuales impera una mentalidad tradicional proclive a las ventas en el mercado interno a niveles acordes con el precio medio de la uva. En cualquier caso, al igual que en España, un cada vez más numeroso grupo de empresas, en su inmensa mayoría con vinos DOP o IGP, vienen protagonizando el aumento de la producción apuntado y la creciente exportación, vital para compensar la caída del consumo interior.

6) La fortísima implantación de vinos con vinculación geográfica. Con datos de 2014, en torno al 92\% de la producción vinícola de la región presenta dicha conexión, el 84\% a través de DOP y el $8 \%$ vía IGP, siendo Valladolid, Burgos, Segovia, Soria y Zamora las provincias donde resulta más marcada, en contraste con Ávila (donde no hay producción con DOP) y Palencia (donde no hay producción con IGP).

Tabla 8

Exportaciones recientes de vino de las regiones españolas (mosto incluido), 2014-2015

\begin{tabular}{|c|c|c|c|c|c|c|c|c|c|c|c|c|}
\hline \multirow{2}{*}{ REGIONES } & \multicolumn{5}{|c|}{ VALOR } & \multicolumn{5}{|c|}{ VOLUMEN } & \multicolumn{2}{|c|}{ PRECIO MEDIO } \\
\hline & 2014 & 2015 & Var 14/15 & (\%) 2014 & (\%) 2015 & 2014 & 2015 & Var 14/15 & (\%) 2014 & (\%) 2015 & 2014 & 2015 \\
\hline Andalucía & 120.164 .720 & 119.824 .262 & $-0,28$ & 4,18 & 4,06 & 51.161 .971 & 52.415 .094 & 2,45 & 1,91 & 1,90 & 2,35 & 2,29 \\
\hline Aragón & 100.976 .361 & 112.948 .150 & 11,86 & 3,51 & 3,82 & 52.137 .091 & 58.938 .858 & 13,05 & 1,95 & 2,13 & 1,94 & 1,92 \\
\hline Asturias & 1.168 .170 & 1.413 .495 & 21,00 & 0,04 & 0,05 & 500.932 & 328.529 & $-34,42$ & 0,02 & 0,01 & 2,33 & 4,30 \\
\hline Baleares & 5.823 .977 & 5.957 .118 & 2,29 & 0,20 & 0,20 & 734.104 & 858.333 & 16,92 & 0,03 & 0,03 & 7,93 & 6,94 \\
\hline Canarias & 3.700 .053 & 3.731 .420 & 0,85 & 0,13 & 0,13 & 437.777 & 427.484 & $-2,35$ & 0,02 & 0,02 & 8,45 & 8,73 \\
\hline Cantabria & 107.954 & 15.269 & $-85,86$ & 0,004 & 0,001 & 54.607 & 3.499 & $-93,59$ & 0,002 & 0,000 & 1,98 & 4,36 \\
\hline Castilla y León & 144.813 .483 & 150.619 .701 & 4,01 & 5,04 & 5,10 & 32.861 .445 & 31.492 .386 & $-4,17$ & 1,23 & 1,14 & 4,41 & 4,78 \\
\hline Castilla-La Mancha & 686.968 .244 & 682.206 .857 & $-0,69$ & 23,91 & 23,10 & 1.384.232.161 & 1.432 .004 .495 & 3,45 & 51,77 & 51,83 & 0,50 & 0,48 \\
\hline Cataluña & 603.082 .576 & 648.028 .305 & 7,45 & 20,99 & 21,94 & 238.672 .304 & 241.931 .229 & 1,37 & 8,93 & 8,76 & 2,53 & 2,68 \\
\hline Comunidad Valenciana & 215.906 .533 & 224.919 .214 & 4,17 & 7,51 & 7,61 & 232.772 .512 & 268.222.834 & 15,23 & 8,71 & 9,71 & 0,93 & 0,84 \\
\hline Extremadura & 101.285 .752 & 98.998 .305 & $-2,26$ & 3,53 & 3,35 & 249.786 .761 & 250.554 .253 & 0,31 & 9,34 & 9,07 & 0,41 & 0,40 \\
\hline Galicia & 40.152 .051 & 42.561 .442 & 6,00 & 1,40 & 1,44 & 25.051 .261 & 26.422 .955 & 5,48 & 0,94 & 0,96 & 1,60 & 1,61 \\
\hline Madrid & 43.151 .160 & 43.959 .986 & 1,87 & 1,50 & 1,49 & 20.727 .643 & 21.076 .011 & 1,68 & 0,78 & 0,76 & 2,08 & 2,09 \\
\hline Murcia & 193.804 .892 & 175.709 .559 & $-9,34$ & 6,75 & 5,95 & 168.490 .018 & 155.259 .049 & $-7,85$ & 6,30 & 5,62 & 1,15 & 1,13 \\
\hline Navarra & 74.246 .917 & 78.772 .389 & 6,10 & 2,58 & 2,67 & 39.664 .555 & 41.312 .671 & 4,16 & 1,48 & 1,50 & 1,87 & 1,91 \\
\hline País Vasco & 196.258.178 & 203.477.295 & 3,68 & 6,83 & 6,89 & 56.358 .498 & 58.250 .237 & 3,36 & 2,11 & 2,11 & 3,48 & 3,49 \\
\hline Rioja (La) & 330.964 .332 & 351.605 .853 & 6,24 & 11,52 & 11,90 & 116.825 .914 & 121.822.312 & 4,28 & 4,37 & 4,41 & 2,83 & 2,89 \\
\hline Otros (sin regionalizar) & 10.500 .348 & 9.022 .940 & $-14,07$ & 0,37 & 0,31 & 3.262 .975 & 1.557 .857 & $-52,26$ & 0,12 & 0,06 & 3,22 & 5,79 \\
\hline EXPORT.TOTAL ESPAÑA & 2.873 .075 .701 & 2.953 .771 .560 & 2,81 & 100,00 & 100,00 & 2.673 .732 .529 & 2.762 .878 .086 & 3,33 & 100,00 & 100,00 & 1,07 & 1,07 \\
\hline
\end{tabular}

Fuente: Observatorio Español del Mercado del Vino.

\subsection{La proyección internacional de la industria vinícola castellana y leonesa}

A las anteriores características cabe añadir una proyección internacional en rápido aumento, pero aún claramente insuficiente. Como se observa en la Tabla 8, las exportaciones en volumen de Castilla y León en 2015 (31,5 millones de litros, mosto y vinagre incluidos) representan tan sólo el 1,14\% del conjunto nacional (el $1,23 \%$ en 2014). Gracias al elevado precio medio de venta al exterior, 4,78 $€$ 
-muy superior al 1,07 de España-, el porcentaje en términos de valor sobre el total para España asciende al 5,1\%.

Figura 8

Evolución de las exportaciones de vino de Castilla y León (2000-2015)

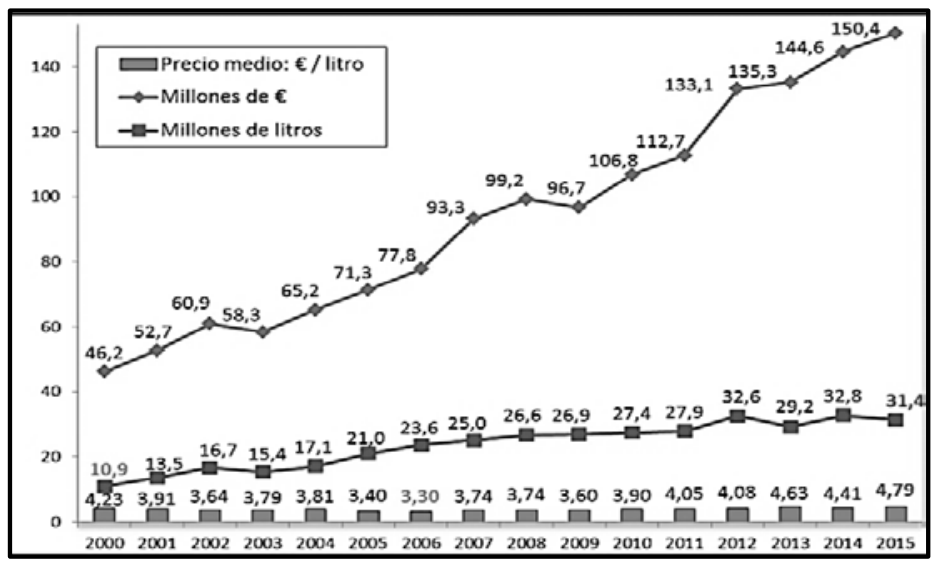

Fuente: Observatorio Español del Mercado del Vino.

Con todo, los 150,4 millones de euros alcanzados en $2015^{10}$ constituyen un record histórico en materia de exportación para Castilla y León, pese a la caída en volumen respecto al año anterior (-4,2\%). Ello es fruto de una casi ininterrumpida y acelerada trayectoria ascendente (Figura 8), de la que cabe señalar al menos un par de detalles:

- En 2000, las ventas al exterior en volumen alcanzaban los 10,9 millones de litros. Ello suponía el 1,08\% del total nacional, porcentaje muy similar al actual 1,14\% (de hecho, la máxima participación se dio en 2006: 1,49\%). Esa cifra se ha triplicado desde entonces, aumentando -incluso durante la crisis (salvo en 2013)- a una tasa de crecimiento anual compuesto del 7,3\%, por encima de la media nacional del 6,9\% y sólo superada por Castilla-La Mancha (11,4\%) y Murcia (7,6\%).

- Las exportaciones en valor, 46,2 millones de euros en 2000, se han multiplicado, a diciembre de 2015, por 3,25, lo que supone una expansión anual compuesta del 8,2\%, con mayor diferencia sobre el promedio español (5,3\%) y sólo inferior a las de Baleares (17,2\%), Asturias (10,5\%), Murcia (10,5\%) y Castilla-La Mancha (8,4\%). Esta progresión, que ha llevado a la región de representar el 3,39\% del total nacional, en 2000, al

${ }^{10}$ Las exportaciones netas de vino, mosto y vinagre en volumen ascienden en 2015 a 31.433.680, 99.863 y 7.695 litros, respectivamente. En términos valor dichas cifras son: 150.426.921, 142.286 y 50.494 euros, respectivamente. 
$5,1 \%$ anteriormente indicado, obedece a una alineamiento en el segmento de los vinos de calidad, en detrimento de vinos de mesa y a granel (a diferencia de regiones como Castilla-La Mancha, Comunidad Valenciana y Extremadura), con un precio medio desde 2011 por encima de los 4 euros el litro y sólo superado por Baleares y Canarias ${ }^{11}$.

Figura 9

Principales destinos de las exportaciones de vino de Castilla y León, 2015



Fuente: Elaboración propia, a partir de los datos del Observatorio Español del Mercado del Vino.

Como puede apreciarse en la Figura 9, la presencia del vino castellano y leonés abarca países de muy diferentes zonas geográficas, siendo actualmente los destinos principales Suiza -con 25,2 millones de euros (el máximo importe)y Alemania (con más de 7 millones de litros y 24 millones de euros); ambos concentran en torno a un tercio de las exportaciones, tanto en términos de volumen como en valor. A continuación se sitúan Estados Unidos, Países Bajos, México (quinto en volumen), Portugal (quinto en valor) y una ascendente China. Los precios medios de exportación más elevados se dan en Hong-Kong (16,2 euros por litro), México $(10,2)$ República Dominicana $(9,0)$ y Suiza $(7,7)$, en tanto que el mínimo se da en Portugal $(0,9)$.

${ }^{11}$ Castilla y León se sitúa entre las regiones que han aumentado sus exportaciones, entre 2000 y 2015, tanto en volumen como en valor. Se trata del grupo más numeroso; de hecho todas ganan en valor, excepto Cantabria, con una tasa de decrecimiento anual compuesto del $-5,1 \%$. En volumen, registran descensos, además de Cantabria (-12,4\%), Canarias $(-16,4 \%)$, Baleares (-2,9\%), Andalucía (-2,3\%) y Galicia (-0,5\%). 
Por provincias, como se pone de relieve en la Figura 10, el grueso de las exportaciones de 2015 se concentra, en línea con lo señalado respecto a la producción, en Valladolid (44\% en volumen y 59,1\% en valor), seguida de Burgos. No obstante, cabe apuntar una mayor dispersión que hace años. De hecho, en 2000, Valladolid aglutinaba porcentajes respectivos del 71,9\% y 72,9\%, pero en los últimos años Burgos, Zamora, Segovia y León han ido experimentando importantes aumentos en sus exportaciones.

\section{Figura 10}

Distribución provincial de las exportaciones de vino de Castilla y León, 2015

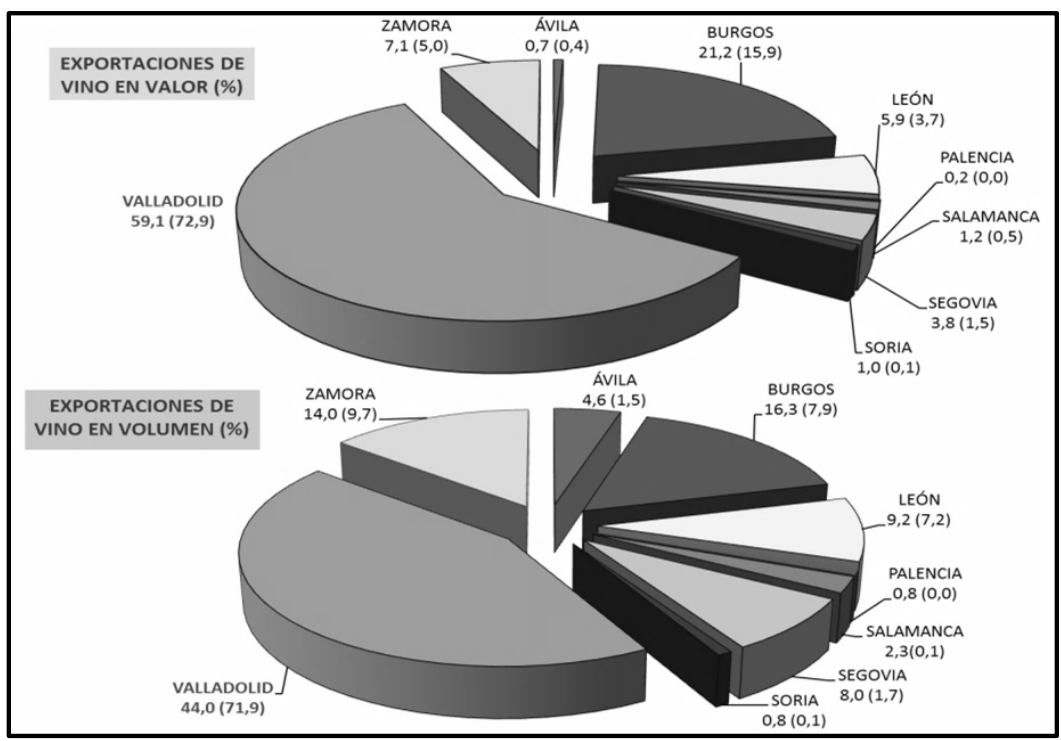

Fuente: Elaboración propia, a partir de los datos del Observatorio Español del Mercado del Vino. Las cifras entre paréntesis son los porcentajes correspondientes al año 2000.

Por tipos de vino, la Figura 11 refleja un indiscutible protagonismo de los vinos con Denominación de Origen, que representan el 81,9\% de la exportación total en valor y el $65,5 \%$ en volumen; porcentajes que ascienden al 93,2\% y al $80 \%$, respectivamente, si se incorporan las cifras relativas a los vinos con Indicación Geográfica Protegida (Vinos de la Tierra de Castilla y León). Tales cifras se hallan en sintonía con el elevado precio medio anteriormente indicado, el cual también es resultado del absoluto predominio del vino embotellado en detrimento del vino vendido a granel y en envases de más de 2 litros, que, en 2015, supone el 9,7\% del total exportado en volumen y únicamente el 1,95 en valor. 
Figura 11

Exportaciones de Castilla y León por tipos de vino, 2015

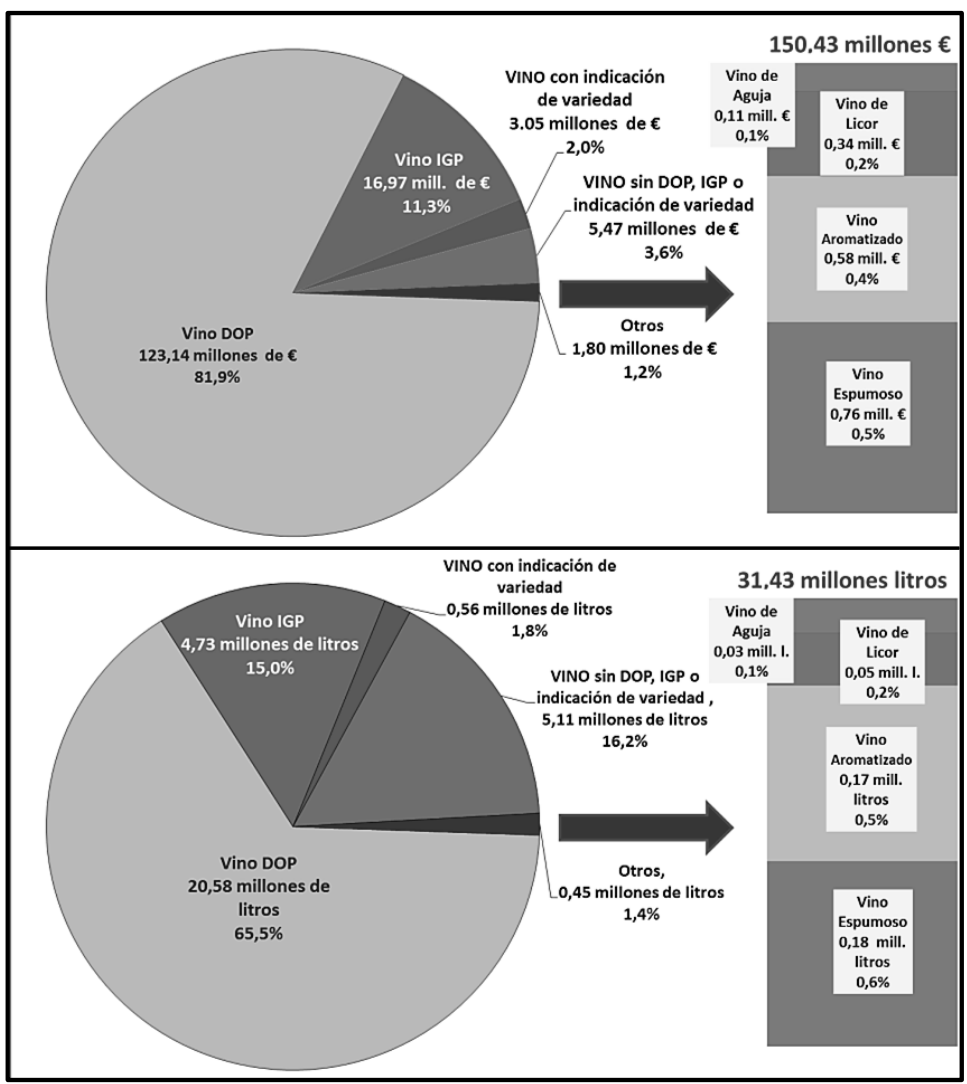

Fuente: Elaboración propia, a partir de los datos del Observatorio Español del Mercado del Vino.

Ese predominio de los vinos con calificación DOP o IGP se debe, en gran medida, al esfuerzo de un cada vez más numeroso grupo de PYMES que, al igual que en el conjunto de España, vienen protagonizando el aumento de la producción apuntado y la creciente exportación, vital para contrarrestar la debilidad del consumo en los mercados regional y nacional.

En este sentido, la Tabla 9 ofrece un elenco de las 35 mayores, por montante de facturación en 2014. Como puede observarse, hasta 20 se localizan en Valladolid, 7 en Burgos, 3 en Segovia y el resto repartidas por otras cuatro provincias, preferentemente en áreas con Denominación de Origen ${ }^{12}$. Su nivel de

${ }^{12}$ La primera de las empresas vinícolas, Bodegas Protos, ocupa el puesto número 192 en el ranking de ventas de las empresas de Castilla y León de 2014. Una clasificación liderada por las cinco grandes empresas de automoción (Renault España, Grupo Antolín, Nissan Motor Ibérica, 
ventas oscila entre los 31 millones de euros de la peñafielense Bodegas Protos y los 3,86 de la quintanillera Dominio de Pingus. En cuanto al número de empleados, el rango va de los 160 del Grupo Matarromera -seguida de Hijos de Antonio Barceló con 129- a los cuatro de las Bodegas y Viñedos Mayor de Castilla y a tan sólo dos en las Bodegas Navalón. En cualquier caso, adquiere interés, en este ámbito, el análisis de las actuaciones implementadas por la Junta de Castilla y León para el fomento del sector, en el marco general de sus planes de promoción de la IAA regional y del Programa de Apoyo 2014-2018 al sector vitivinícola español.

Tabla 9

Las 35 mayores empresas vitivinícolas de Castilla y León, en volumen de ventas

\begin{tabular}{|c|c|c|c|c|}
\hline RAZÓN SOCIAL & $\begin{array}{c}\text { LUGAR } \\
\text { RANKING }\end{array}$ & VENTAS & EMPLEO & UBICACIÓN/SEDE \\
\hline Bodegas Protos & 192 & 31,13 & 57 & Peñafiel (VA) \\
\hline Hijos de Antonio Barceló & 228 & 26,12 & 129 & Quintanilla de Onésimo (VA) \\
\hline Bodegas Vega-Sicilia & 242 & 24,53 & 89 & Valbuena de Duero (VA) \\
\hline Bodega Cuatro Rayas & 282 & 21,00 & 60 & La Seca (VA) \\
\hline Grupo Matarromera & 308 & 19,30 & 160 & Valbuena de Duero (VA) \\
\hline Pago de Carraovejas & 330 & 18,29 & 48 & Peñafiel (VA) \\
\hline Avelino Vegas & 367 & 16,09 & 28 & Santiuste de San Juan Bautista (SG) \\
\hline United Wineries Estates & 387 & 15,00 & 65 & Valverdón (SA) \\
\hline Cocope & 413 & 14,03 & 21 & Peñafiel (VA) \\
\hline Bodegas Arlanza & 423 & 13,90 & 18 & Villalmanzo (BU) \\
\hline Bodegas Emilio Moro & 483 & 11,98 & 2 & Pesquera de Duero (VA) \\
\hline Alejandro Fernández Tinto Pesquera & 541 & 10,57 & 30 & Pesquera de Duero (VA) \\
\hline Bodegas Grupo Yllera & 550 & 10,27 & 50 & Rueda (VA) \\
\hline Altos de Ontañón & 592 & 9,64 & 7 & Fuentecén (BU) \\
\hline Hijos de Alberto Gutiérrez & 811 & 6,94 & 26 & Serrada (VA) \\
\hline Bodegas y Viñedos Alión & 850 & 6,68 & 12 & Peñafiel (VA) \\
\hline Santa Rosalía Gourmet & 878 & 6,42 & 30 & Revilla Vallejera (BU) \\
\hline Agrovitivinícola Negredo & 923 & 6,12 & 11 & Palenzuela $(P)$ \\
\hline Bodegas Fariña & 933 & 6,03 & 59 & Casaseca de las Chanas (ZA) \\
\hline Bodegas Señorío de Nava & 935 & 6,03 & 18 & Nava de Roa (BU)/Armunia (LE) \\
\hline Bodegas Arzuaga Navarro & 965 & 5,89 & 42 & Quintanilla de Onésimo/Lerma (BU) \\
\hline Selección de Torres & 981 & 5,78 & 9 & Fompedraza (VA) \\
\hline Bodegas Mauro & 1015 & 5,58 & 18 & Tudela de Duero (VA) \\
\hline
\end{tabular}

Michelin España Portugal e Iveco España). En relación con la IAA, la primera firma es el grupo burgalés Campofrío Alimentación (en el $8^{\circ}$ lugar del ránking), seguido de Calidad Pascual, Grupo Siro, Galletas Gullón y la agropecuaria Cobadú. La estructura empresarial es variada a semejanza de España. En medio del entorno de PYMES familiares, hay un grupo cooperativo tradicionalmente importante (por ejemplo en Rueda, la Ribera del Duero burgalesa y Toro) y hay también empresas pujantes que han extendido su presencia a otras áreas, como el Grupo Matarromera, Alejandro Fernández Tinto Pesquera o Hijos de Antonio Barceló; otras forman parte de holdings con sede en el exterior, como Abadía de Retuerta, perteneciente al grupo farmacéutico Novartis, o Vega-Sicilia, integrada en el holding El Enebro, que en 2015 trasladó su sede a Londres. En cualquier caso, algunas de las más pujantes, entre ellas las citadas, se sitúan en la llamada "milla de oro" del vino español, entre las localidades vallisoletanas de Tudela de Duero y Peñafiel. Importantes en dicha área también son Emilio Moro, Pago de Carraovejas, Cocope, Arzuaga Navarro, Alión, Dominio de Pingus y Bodegas Mauro. 
Tabla 9 (continuación)

Las 35 mayores empresas vitivinícolas de Castilla y León, en volumen de ventas

\begin{tabular}{|c|c|c|c|c|}
\hline RAZON SOCIAL & $\begin{array}{c}\text { LUGAR } \\
\text { RANKING }\end{array}$ & VENTAS & EMPLEO & UBICACIÓN/SEDE \\
\hline Bodegas y Viñedos Mayor de Castilla & 1050 & 5,43 & 4 & Serrada (VA) \\
\hline Diez Siglos de Verdejo & 1055 & 5,38 & 12 & Serrada (VA) \\
\hline Cooperativa Duero-Arlanza & 1080 & 5,24 & 20 & Lerma (BU) \\
\hline Viña Buena & 1085 & 5,23 & 5 & Fuentepelayo (SG) \\
\hline Bodegas Corona & 1122 & 5,05 & 20 & Zamora \\
\hline Bodegas Navalón & 1128 & 5,03 & 2 & León \\
\hline Bodegas Hermanos Pérez Pascuas & 1174 & 4,82 & 20 & Pedrosa de Duero (BU) \\
\hline Abadía Retuerta & 1181 & 4,80 & 97 & Sardón de Duero (VA) \\
\hline Bodegas José Pariente & 1201 & 4,74 & 7 & La Seca (VA) \\
\hline Bodegas Cerrosol & 1382 & 4,10 & 10 & Santiuste de San Juan Bautista (SG) \\
\hline Bodegas Viña Vilano & 1427 & 4,00 & 20 & Pedrosa de Duero (BU) \\
\hline Dominio de Pingus & 1486 & 3,86 & 8 & Quintanilla de Onésimo (VA) \\
\hline
\end{tabular}

Fuente: Elaboración propia, a partir de los datos de la revista Castilla y León Económica, n ${ }^{\circ}$ 237, febrero de 2016.

Dada la trascendencia de los vinos de calidad con designación geográfica específica en la producción y comercialización exterior de la región, a continuación se analizan sus rasgos fundamentales, así como su proyección exportadora, en una sección diferenciada.

\subsection{Exportaciones y vinculación vino-territorio en Castilla y León}

El nexo entre vino y territorio en la región viene fundamentalmente representado por sus Denominaciones de Origen y de Calidad con Indicación Geográfica delimitada ${ }^{13}$, algunos de cuyos indicadores principales se recogen en la Tabla 10. Como puede apreciarse, dos, de las doce existentes, Ribera del Duero y Rueda, destacan ampliamente sobre las demás respecto a las diferentes variables consideradas. No en vano, forman parte, como ya se ha visto, del grupo de las 20 primeras DOP españolas. Ambas concentran el 71,9\% de la superficie total de viñedo con DOP, el 64,3\% del número total de viticultores y el 58,2\% del número de bodegas adscritas a las 12 Denominaciones, al tiempo que el $87 \%$ de su comercio interior, en volumen y en valor.

Les siguen en importancia, pero a notable distancia, Toro, Bierzo, Cigales y Tierra de León, ocupando las posiciones más rezagadas las zonas de los llamados, hasta hace poco tiempo, Vinos de Calidad con Indicación Geográfica:

${ }^{13}$ Los vinos juegan un gran papel en el variado contexto de las Denominaciones de Calidad de los productos agroalimentarios de la región (MERCASA). De sus 54 Denominaciones de Calidad 16 corresponden a productos cárnicos, 13 a vinos (las 12 DOP analizadas más la IGP Vinos de Castilla y León), 10 a frutas y verduras, 5 a quesos y lácteos y otras 5 a legumbres, como grupos de alimentos más destacados. Castilla y León, junto con Andalucía, Cataluña, Aragón y la Comunidad Valenciana, constituye, merced a su extensión geográfica, una de las más destacadas en este ámbito. 
Valles de Benavente, Valtiendas, y Sierra de Salamanca; las tres cuentan con menos de 10 bodegas y una reducida superficie de cultivo, especialmente las dos últimas que no llegan a las 100 hectáreas.

Tabla 10

Vinos con DOP en Castilla y León: principales indicadores, 2015

\begin{tabular}{|c|c|c|c|c|c|c|c|c|c|c|c|c|}
\hline DENOMINACIÓN DE ORIGEN &  & 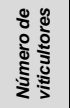 & 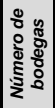 & 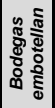 &  & 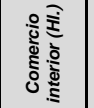 & 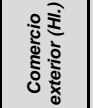 & 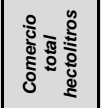 & 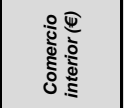 & 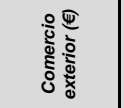 & 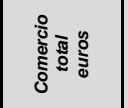 & 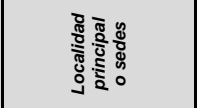 \\
\hline ARLANZA & 347 & 267 & 16 & 16 & 0 & 2.539 & 236 & 2.775 & 888.388 & 89.896 & 978.284 & Lerma \\
\hline ARRIBES & 337 & 266 & 14 & 10 & 4 & 2.238 & 886 & 3.124 & 671.505 & 265.767 & 937.272 & Fermoselle/Aldeadávila \\
\hline BIERZO & 2.982 & 2.400 & 77 & 60 & 17 & 67.659 & 13.790 & 81.449 & 27.063 .600 & 6.205 .500 & 33.269 .100 & Cacabelos/Ponferrada \\
\hline CIGALES & 2.034 & 434 & 34 & 34 & 0 & 21.405 & 6.296 & 27.701 & 8.562 .056 & 3.355 .723 & 11.917 .779 & Cigales \\
\hline RIBERA DEL DUERO & 21.964 & 8.254 & 307 & 271 & 36 & 587.567 & 84.012 & 671.579 & 293.783 .500 & 71.111 .924 & 364.895 .424 & Peñafiel/Roa de Duero \\
\hline RUEDA & 12.995 & 1.516 & 69 & 59 & 10 & 623.435 & 85.867 & 709.302 & 155.858 .565 & 21.466 .750 & 177.325 .315 & Rueda \\
\hline TIERRA DE LEÓN & 1.359 & 306 & 40 & 40 & 0 & 16.573 & 169 & 16.742 & 7.734 .067 & 112.723 & 7.846 .790 & Valencia de Don Juan \\
\hline TIERRA DEL VINO DE ZAMORA & 649 & 190 & 10 & 10 & 0 & 592 & 233 & 825 & 324.394 & 233.116 & 557.510 & Villanueva de Campeán \\
\hline TORO & 5.474 & 1.350 & 60 & 60 & 0 & 56.313 & 24.134 & 80.447 & 24.053 .695 & 10.343 .143 & 34.396 .838 & Toro \\
\hline SIERRA DE SALAMANCA & 90 & 91 & 6 & 6 & 0 & 415 & 276 & 691 & 221.551 & 297.576 & 519.127 & Sequeros \\
\hline VALTIENDAS $(*)$ & 78 & 14 & 6 & 6 & 0 & 960 & 7 & 967 & 384.000 & 3.000 & 387.000 & Valtiendas \\
\hline TOTAL CASTILLA Y LEÓN & 48.590 & 15.185 & 646 & 579 & 67 & 1.380 .715 & 216.248 & 1.596 .963 & 519.747 .599 & 113.580 .037 & 633.327 .636 & \\
\hline TOTAL ESPAÑA & 574.038 & 123.617 & 4.120 & 3.483 & 637 & 6.804 .299 & 4.779 .097 & 11.583 .396 & 1.745 .974 .822 & 1.460 .766 .297 & 3.206.741.119 & \\
\hline CASTILLA Y LEÓN/ESPAÑA (\%) & 8,46 & 12,28 & 15,68 & 16,62 & 10,52 & 20,29 & 4,52 & 13,79 & 29,77 & 7,78 & 19,75 & \\
\hline
\end{tabular}

Fuente: Elaboración propia, a partir de los datos del MAGRAMA.

Dicha jerarquía se reproduce en el comercio exterior, donde, en 2015, la Ribera del Duero y Rueda alcanzan cotas muy similares en volumen, con más de 80.000 hectolitros cada una (reuniendo el 78,6\% de las exportaciones totales de las 12 DOP, que ascienden a 216.248 hectolitros), pero con sensibles diferencias en valor. De hecho, la Ribera del Duero, con un promedio de 8,50 euros, frente a los 2,50 de Rueda, cuenta con el precio de exportación más alto de las 20 principales DOP de España, por encima de la media nacional $(3,10)$, y de los vinos de Rioja $(4,30)$ y del Penedés $(7,60)$. Esta situación es resultado de la favorable trayectoria de ambas zonas en los últimos años, reflejada en la Figura 12 en términos de volumen.

Aunque con visible impacto de la crisis, sobre todo en la Ribera del Duero (en 2008-2009 y 2012), la evolución es realmente dinámica, habiéndose cuadruplicado en quince años la exportación en Rueda y multiplicado casi por diez en la Ribera, con sendas tasas de crecimiento anual compuesto del $11,6 \%$ y el 17,4\% para el conjunto del periodo. Toro -con marcados altibajos- crece al $10,5 \%$, en tanto que, con ritmos más intensos, Bierzo (24,5\%) y Cigales (23,5\%, especialmente entre 2001 y 2007) han incrementado su presencia internacional, aunque con valores absolutos mucho más modestos, circunstancia asimismo constatable en Arlanza y Arribes, desde 2006, y Sierra de Salamanca, desde 2011. 
En esta última zona, de hecho, se da, en 2015, la mayor intensidad exportadora, con el $40 \%$ del vino comercializado en volumen, y el 57\% en valor, destinado el exterior. También Toro (30\% en especie y en dinero), Tierra del Vino de Zamora, Arribes y Valles de Benavente presentan porcentajes superiores al 25\% para ambos casos, por encima de los relativos a la Ribera del Duero (12,5\% y 19,5\%) y Rueda (12,1\% en ambas variables). La menor orientación internacional se da en Valtiendas y Tierra de León.

Figura 12

Evolución de las exportaciones de vino en las DOP de Castilla y León (2000-2015)

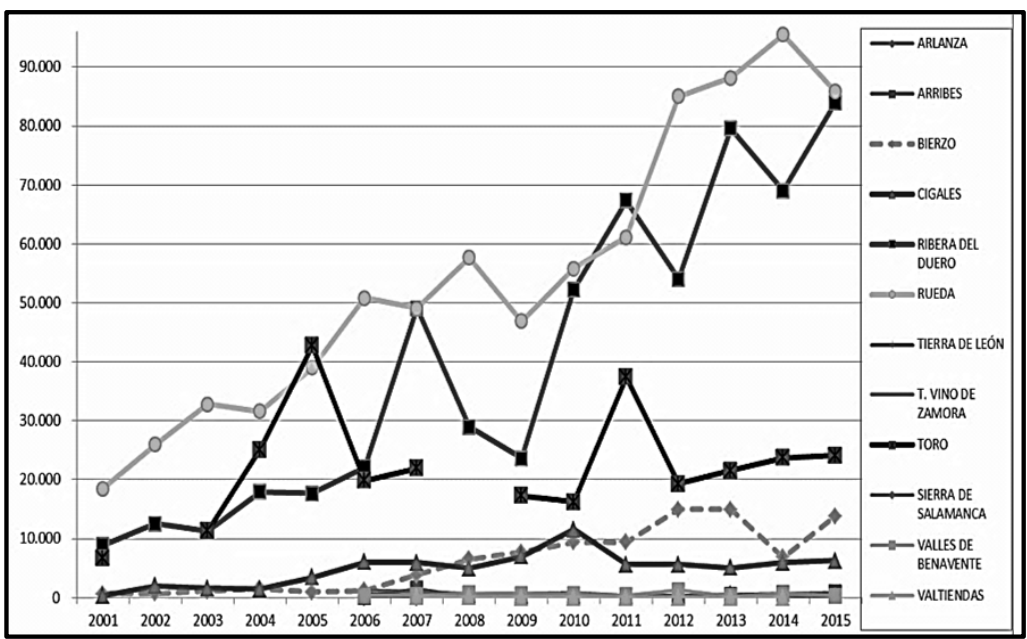

Nota: No hay datos para Toro en 2002 y 2008.

Fuente: Elaboración propia, a partir de los datos (en hectolitros) del MAGRAMA.

En todo caso, de dicha evolución resulta un reparto territorial de las exportaciones muy concentrado. Como refleja la Figura 13, entre 2011 (año a partir del cual hay datos para las 12 DOP) y 2015, la Ribera del Duero y Rueda aglutinan el 77,4\% de las exportaciones en volumen, cifra que se eleva al 86\% en valor desde 2012 (a falta de datos para Bierzo y Rueda en 2011). Si se incluye la IGP Vinos de la Tierra de Castilla y León, cuya proyección exterior ha aumentado muy notablemente en los últimos años ${ }^{14}$, tal concentración disminuye apreciablemente.

Así, en 2015, la IGP reúne el 20,3\% de las exportaciones en volumen de vinos de calidad con denominación geográfica, suponiendo el dúo Rueda-Ribera

${ }^{14}$ En 2012, las exportaciones de la IGP Castilla y León, suponían sólo el 2,1\% en volumen y el 6,3\% de las realizadas por el conjunto de IGP españolas. En 2015, con 55.000 hectolitros exportados, por un importe 11 millones de euros, dichos porcentajes son 10,9\% y 14,8\%, respectivamente, representando un tercio del comercio total de la IGP. 
del Duero el $62,6 \%{ }^{15}$. No ocurre lo mismo, sin embargo, en términos de valor: la IGP representa ahora el 8,8\%, en razón de su más modesto precio medio (2 euros por litro), similar al peso de Toro (8,3\%), pero muy inferior al de Rueda $(17,2 \%)$ y, sobre todo, de la Ribera $(57,1 \%)$.

Figura 13

Distribución territorial de las exportaciones en volumen de los vinos con DOP en Castilla y León (2011-2015)

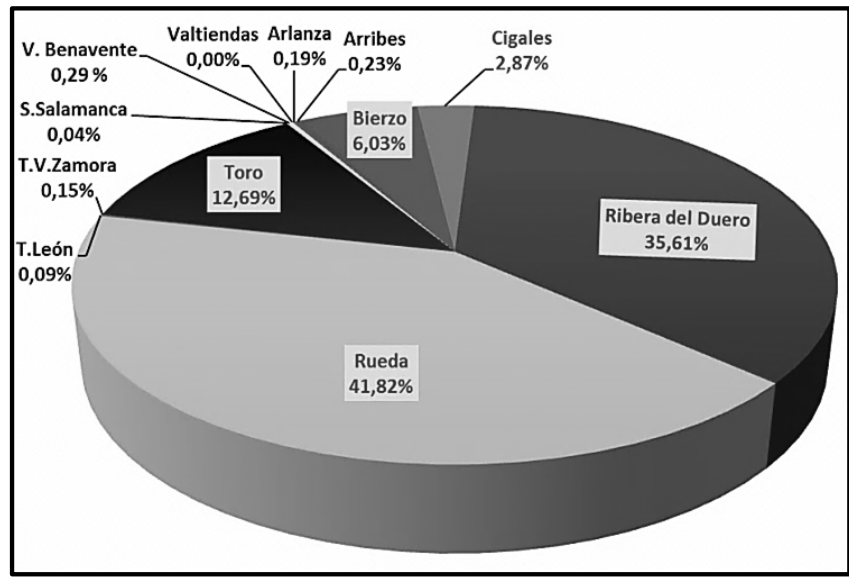

Fuente: Elaboración propia, a partir de los datos del MAGRAMA.

Los mayores precios de venta se dan en Sierra de Salamanca y Tierra del Vino de Zamora, con cifras que alcanzan en 2015 los 10 euros por litro en el comercio exterior, fruto de una producción limitada y de calidad, apreciada en EE.UU. merced a la pericia de algunos comerciales (y los 5 euros en el interior), superando incluso los 8,50 de la Ribera del Duero. Por encima de los 5 euros se sitúan Tierra de León $(6,70)$ y Cigales $(5,30)$. Los precios de exportación más modestos se dan en Rueda $(2,50)$, Benavente $(2,80)$ y Arribes (3 euros).

En la Tabla 11 se ofrece detalle del comercio interior y exterior por tipos de vino en las 12 DOP. Rueda es la única zona productora de toda la gama de vinos, aunque con predominio abrumador de los blancos en ambos tipos de comercio; espumosos y de aguja superan en peso a tintos y rosados en el comercio interior, siendo también objeto de exportación. Los rosados destacan en Cigales, Tierra de León y Valles de Benavente, constituyendo mayoría en las

${ }^{15}$ La distribución de las exportaciones en volumen de 2015 es la siguiente: Rueda, 31,65\%; Ribera del Duero, 30,97\%; IGP Castilla y León, 20,29\%; Toro, 8,90\%; Bierzo, 5,08\%; Cigales, 2,32\%; Arribes, 0,33\%; Valles de Benavente, 0,13\%; Sierra de Salamanca, 0,10\%; Arlanza y Tierra del Vino de Zamora, 0,09\%; Tierra de León, 0,06\% y Valtiendas, que no presenta dato para dicho año, pero que en 2014 exportó únicamente 7 hectolitros. En valor, Bierzo supone el 4,98\%, Cigales el 2,69\% , y los demás se sitúan por debajo del 0,24\% de Sierra de Salamanca. 
exportaciones de esta última zona. En el resto, domina el tinto, sobre todo en la Ribera del Duero (donde no hay blancos y los rosados son una pequeña parte de lo comercializado). Cabe señalar la presencia de blancos en Toro, Tierra de León y Bierzo (donde un 9\% es objeto de exportación).

Tabla 11

DOP en Castilla y León: comercio interior y exterior por tipos de vino, 2015

\begin{tabular}{|c|c|c|c|c|c|c|c|c|c|c|c|c|c|}
\hline \multirow{2}{*}{$\begin{array}{c}\text { DENOMINACIÓN DE ORIGEN } \\
\text { VINOS DE CALIDAD }\end{array}$} & \multicolumn{6}{|c|}{ Comercio Interior 2014-2015 } & \multicolumn{6}{|c|}{ Comercio Exterior 2014-2015 } & \multirow{2}{*}{\begin{tabular}{|l|} 
Com.total \\
$2014 / 2015$ \\
\end{tabular}} \\
\hline & Blanco & Rosado & Tinto & De licor & \begin{tabular}{|l|} 
Espum. \\
IAguja
\end{tabular} & total & Blanco & Rosado & Tinto & De licor & \begin{tabular}{|c|}
$\begin{array}{c}\text { Espum. } \\
\text { Aguja }\end{array}$ \\
\end{tabular} & total & \\
\hline ARLANZA & 61 & 565 & 1.913 & 0 & 0 & 2.539 & 2 & 8 & 226 & 0 & 0 & 236 & 2.775 \\
\hline ARRIBES & 271 & 186 & 1.781 & 0 & 0 & 2.238 & 45 & 1 & 840 & 0 & 0 & 886 & 3.124 \\
\hline BIERZO & 7.083 & 2.311 & 58.265 & 0 & 0 & 67.659 & 629 & 193 & 12.968 & 0 & 0 & 13.790 & 81.449 \\
\hline CIGALES & 100 & 16.088 & 5.217 & 0 & 0 & 21.405 & 0 & 506 & 5.790 & 0 & 0 & 6.296 & 27.701 \\
\hline RIBERA DEL DUERO & 0 & 11.997 & 575.570 & 0 & 0 & 587.567 & 0 & 0 & 84.012 & 0 & 0 & 84.012 & 671.579 \\
\hline RUEDA & 619.190 & 1.054 & 1.381 & 160 & 1.650 & 623.435 & 84.061 & 726 & 891 & 0 & 189 & 85.867 & 709.302 \\
\hline TIERRA DE LEÓN & 1.806 & 10.880 & 3.887 & 0 & 0 & 16.573 & 33 & 14 & 122 & 0 & 0 & 169 & 16.742 \\
\hline TIERRA DEL VINO DE ZAMORA & 293 & 39 & 260 & 0 & 0 & 592 & 67 & 5 & 161 & 0 & 0 & 233 & 825 \\
\hline TORO & 1.960 & 2.499 & 51.854 & 0 & 0 & 56.313 & 0 & 0 & 24.134 & 0 & 0 & 24.134 & 80.447 \\
\hline SIERRA DE SALAMANCA & 0 & 0 & 415 & 0 & 0 & 415 & 0 & 0 & 276 & 0 & 0 & 276 & 691 \\
\hline VALLES DE BENAVENTE & 230 & 476 & 313 & 0 & 0 & 1.019 & 16 & 198 & 128 & 0 & 0 & 342 & 1.361 \\
\hline VALTIENDAS (*) & 0 & 340 & 620 & 0 & 0 & 960 & 0 & 0 & 7 & 0 & 0 & 7 & 967 \\
\hline TOTAL CASTILLA Y LEÓN & 630.994 & 46.435 & 701.476 & 160 & 1.650 & 1.380 .715 & 84.853 & 1.651 & 129.555 & 0 & 189 & 216.248 & 1.596 .963 \\
\hline TOTAL ESPAÑA & 1.705 .555 & 370.679 & 3.762 .620 & 267.772 & 697.673 & 6.804 .299 & 547.323 & 178.594 & 2.622 .159 & 267.343 & 1.163 .678 & 4.779 .097 & 11.583 .396 \\
\hline CASTILLA Y LEÓN/ESPAÑA (\%) & 37,00 & 12,53 & 18,64 & 0,06 & 0,24 & 20,29 & 15,50 & 0,92 & 4,94 & 0,00 & 0,02 & 4,52 & 13,79 \\
\hline
\end{tabular}

Fuente: Elaboración propia, a partir de los datos del MAGRAMA.

La IGP Castilla y León muestra una mayor variedad. De un total de 168 bodegas, las orientadas a la exportación han comercializado 27.147 hectolitros de tinto, lo que supone el 49,3\% del total exportado (muy inferior al 59,9\% referido a las ventas al exterior de tinto de las DOP). Le siguen en importancia el blanco (36,3\%) y el rosado (13,3\%), con reducida presencia del vino de aguja (535 hectolitros) y de los vinos espumoso (4), de licor (6) y aromatizado (2).

Respecto a los principales países importadores de vino DOP de la región, en la Figura 14 se observa la importancia de la UE (que concentra el 58,7\% de las ventas al exterior en volumen acumuladas en los últimos cinco años), con Alemania, Holanda y Reino Unido, en cabeza, seguidas de Bélgica y Dinamarca (este quinteto supone el 47,3\% de la exportación total). También constituyen destinos importantes Estados Unidos, México, Suiza y China; estos dos últimos países junto con Alemania, registran los incrementos más notables en este lustro.

Por territorios, el grueso de las exportaciones se destina, por lo general, a un reducido número de países, lo que reclama un importante esfuerzo diversificador. Así, Arlanza ha vendido principalmente en Suiza (23,5\%), China, EE.UU. y Polonia; Arribes, en China (70,2\%) y Reino Unido; Bierzo, en Alemania (29,8\%) y EE.UU.; Cigales, en Suiza (23,8\%) y Bélgica; Ribera del Duero, en Alemania 
(18\%), Suiza (14\%), EE.UU. y México; Rueda, que junto con la anterior es la que está presente en mayor número de países, en Holanda (24,8\%), Alemania (21,2\%) y EE.UU; Tierra de León, en México (46,5\%) y EE.UU.; Tierra del Vino de Zamora, en EE.UU. (37,7\%) y Brasil; Toro, en Alemania (18\%), Portugal, China y EE.UU.; Sierra de Salamanca, en EE.UU. (63\%) y Reino Unido; Valles de Benavente, en Alemania (27,8\%), Reino Unido, Suecia y China; Valtiendas, la mitad en Suiza y el otro 50\% en EE.UU.; la IGP Castilla y León, en Alemania (20,1\%), Bélgica, Holanda y EE.UU.. Dentro de las exportaciones de las IGP españolas, presenta una posición importante en Suiza, México, Japón y Reino Unido.

Figura 14

Distribución mundial de la exportación de vinos DOP de Castilla y León (2011-2015) (\%)

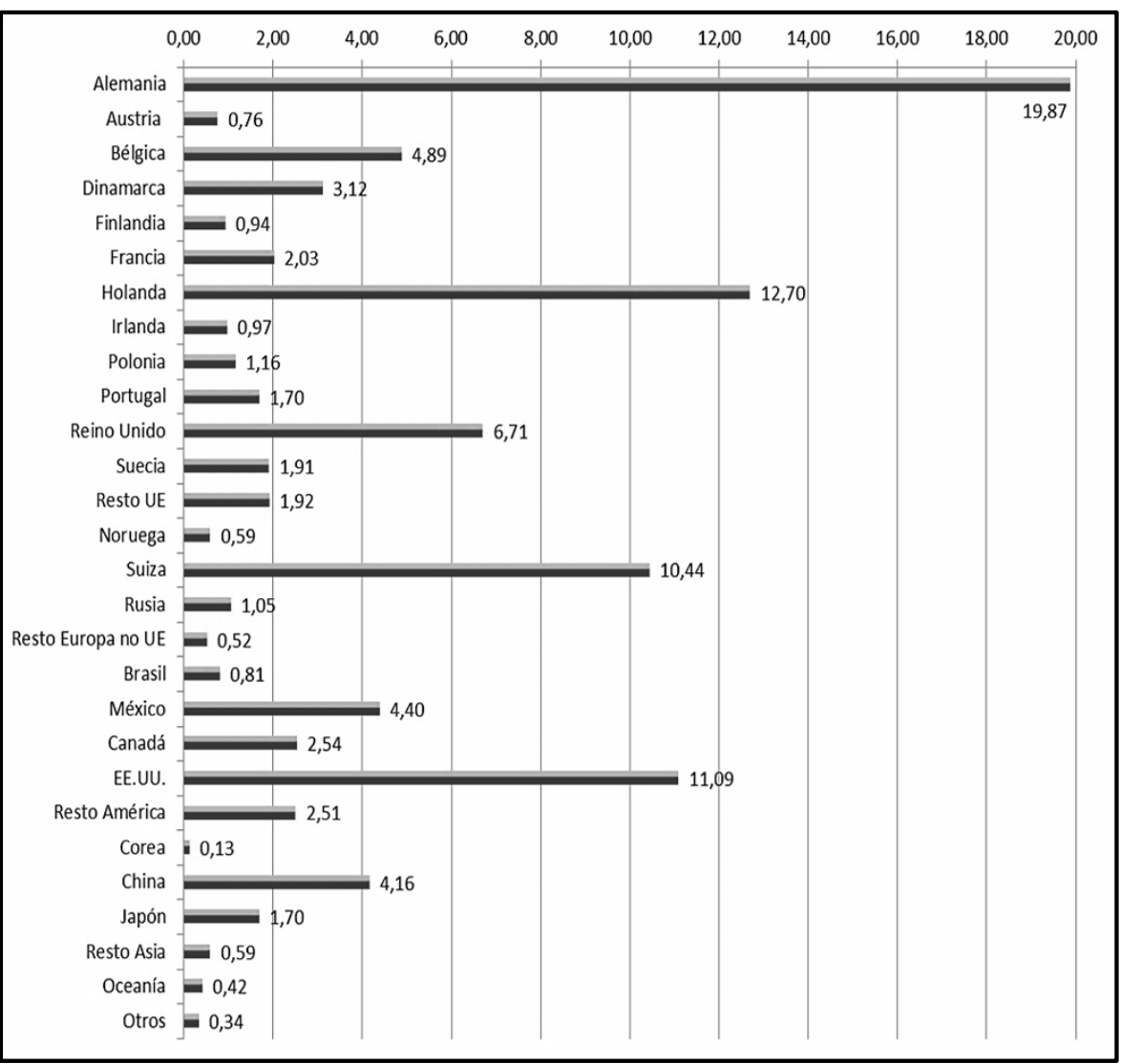

Fuente: Elaboración propia, a partir de los datos del MAGRAMA.

En cualquier caso, la proliferación de estas DOP ha propiciado la aparición de 
un creciente número de empresas, susceptible de configurar SPLA ${ }^{16}$ capaces de generar economías externas a escala comarcal (Zanni, 2004), con base en la producción del vino. Así ocurre en las DOP más antiguas: Ribera del Duero, Rueda y Toro y, potencialmente en Bierzo, Cigales. Su incorporación a las Rutas de Vinos de España (ACEVIN, 2016), constituye una interesante oportunidad de diversificación productiva para estas zonas, a través del enoturismo.

\section{CONSIDERACIONES FINALES}

Del análisis efectuado, cabe extraer, a modo de conclusión, las siguientes consideraciones:

- La IAA constituye una de las palancas básicas de crecimiento en el contexto de la industria nacional y, sobre todo, castellana y leonesa, dada la mayor especialización de la región en la actividad agroalimentaria. Buena prueba de ello es su resistencia frente a la crisis y el mantenimiento en la región de más de 35.000 empleos.

- La industria del vino ocupa un destacado papel, tanto en España como en la región, en el ámbito de la IAA. Con unas 550 empresas y 3.700 empleados, constituye un importante motor generador de actividad económica y cifra de negocio.

- Las industrias vinícolas de España y Castilla y León comparten una serie de rasgos básicos: gran extensión geográfica del viñedo; elevada producción, sujeta a importantes variaciones anuales, ampliamente condicionadas por el clima; fuerte concentración territorial (en La Mancha, para el caso español, y en las provincias de Valladolid y Burgos, para el castellano y leonés); débil consumo interno, intensificado con la crisis, y más acusado en Castilla y León, que impone el reto de captar nichos de mercado en segmentos de población distintos de los consumidores tradicionales; minifundismo empresarial, que dificulta una mayor visibilidad en los mercados, a fin de compensar la caída en el consumo nacional; impulso exportador, manifiestamente mejorable en la región, donde aparece ligado a la venta de vinos de calidad a precios medios superiores a los de casi todas las CC.AA.

- En este difícil contexto han ido cobrando relevancia las estrategias vitivinícolas, para un escenario global, de un puñado de PYMES de origen esencialmente nacional/regional que han configurado un importante grupo eficaz y diversificado, productor tanto de vinos con DOP como de vinos

${ }^{16}$ Existen en la región varias áreas de especialización productiva constitutivas de SPLA (Juste Carrión, 2011): Aranda de Duero, Venta de Baños, Aguilar de Campoo, los chacineros Guijuelo y Cantimpalos-Carbonero el Mayor, y los vinícolas Ribera del Duero, Rueda y Toro. Municipios de interés agroalimentario son también Arévalo y Briviesca. La IAA va ganando terreno asimismo en los SPL de Ponferrada, Medina del Campo, Cuéllar y Béjar (Juste Carrión, 2012). 
más económicos de aceptable calidad, crecientemente ligado a la exportación, al auge de nuevos productos (vinos ecológicos, sin alcohol y de baja graduación o refrescos a base de vino), a la vinculación del vino a la gastronomía y al enoturismo.

- La intensa proyección territorial de la industria vinícola, con un patrón de localización empresarial vinculado a la materia prima, constituye un importante factor de desarrollo local/rural, que encuentra su principal reflejo en la presencia de DOP susceptibles de configurar SPLA, donde fomentar potenciales lazos cooperativos. En Castilla y León, la proliferación, durante las últimas décadas, de bodegas con vinos de calidad (tintos y blancos) en esas zonas, ha afianzado la industria vitivinícola regional dentro del panorama nacional e internacional, hasta el punto de dominar claramente en las exportaciones regionales de vino.

- Así lo demuestra la experiencia de zonas como Ribera del Duero, Rueda o Toro, con algunas de las empresas más prestigiosas a nivel nacional y con presencia en el mercado exterior en un creciente número de países. Su éxito y su arraigo territorial, como exponente de iniciativas de desarrollo local generadoras de empleo y riqueza resultan, sin duda, trascendentales para ayudar a fijar la población rural en una región con un altísimo grado de envejecimiento demográfico actual y con visos de agudizarse en los próximos años.

De cualquier modo, la perdurabilidad del dinamismo del sector y su solidez como factor de desarrollo en Castilla y León (y, por extensión, en España) en los próximos años, está supeditada a la conjugación exitosa de una serie de fortalezas y debilidades, que conforman un estimulante terreno para el desarrollo de futuras investigaciones. Así, resulta de gran interés profundizar en el estudio de las estrategias empresariales en materia de producción, $\mathrm{I}+\mathrm{D}+\mathrm{i}$, comercialización e internacionalización (sobre todo hacia países emergentes) y su grado de agresividad en un sector maduro y fuertemente competitivo, y examinar el impacto sobre las mismas de la apuesta de las instituciones regionales por el sector mediante subvenciones y otros mecanismos (ferias, campañas publicitarias...), en línea con lo previsto en la Agenda Estratégica de Innovación elaborada por la Plataforma Tecnológica del Vino, cara a 2020. Merecen un examen detallado asimismo: el alcance del enoturismo como encrucijada entre vino, patrimonio histórico, cultura gastronómica, artesanía popular y medio rural, en una región que aspira ser líder a escala nacional en este ámbito; el reto del envejecimiento de los viticultores y la escasa incorporación de jóvenes, amén del problema del recambio generacional en las bodegas de carácter familiar; el papel de la Economía Social (cooperativas, sociedades laborales,...) en la rama vinícola regional; los reajustes frente a la burbuja inversora en el sector, previa a la crisis, orientados a la canalización de 
excedentes y las tensas relaciones con el sector distribuidor; el papel de la mujer en los ámbitos del consumo y la producción; y, naturalmente, las actuaciones contempladas con vistas a la sostenibilidad productiva frente al cambio climático.

\section{REFERENCIAS BIBLIOGRÁFICAS}

ALBISU L.M., y ZEBALLOS, G. (2014). "Consumo de vino en España: tendencias y comportamiento del consumidor". En Compés López, R. y Castillo Valero, J.S. (coord.): La economía del vino en España y en el mundo, pp. 99-140. Almería: Cajamar Caja Rural.

ASOCIACIÓN ESPAÑOLA DE CIUDADES DEL VINO (ACEVIN) (2016). Informe de visitantes a bodegas y museos del vino asociados a las Rutas del Vino de España, 2015. Alcázar de San Juan, ACEVIN.

BARCO, E. (2002). "El sector vitivinícola en el siglo XXI". Distribución y Consumo, nº 65, pp. 22-33.

COMPÉS LÓPEZ, R. y CASTILLO VALERO, J.S. (coord.) (2014). La economía del vino en España y en el mundo. Almería: Cajamar Caja Rural.

FERNÁNDEZ, E. y PINILLA, V. (2014). "Historia económica del vino en España (18502000)". En Compés López, R. y Castillo Valero, J.S. (coord.): La economía del vino en España y en el mundo, pp. 67-98. Almería: Cajamar Caja Rural.

JORDANA, J. (2009). "Hacia dónde va la industria agroalimentaria". Mediterráneo Económico, nº 15, pp. 207-227.

JUSTE CARRIÓN, J.J. (2011). "Industria agroalimentaria, desarrollo rural y sistemas productivos locales en Castilla y León". Cuadernos de Estudios Agroalimentarios CEA, vol. 02, julio, pp. 219-253. Fundación Cajamar.

JUSTE CARRIÓN, J.J. (2012). "Análisis del comportamiento del empleo industrial en los sistemas productivos locales en Castilla y León". Revista de Estudios Empresariales, Segunda Época, n¹, p.84-112.

LAGO MONEO, J.A. (2016) (dir.). "El gasto en vino". Boletín de Investigación de Constanza Business \& Protocol School, Documento $n^{\circ}$ 1/2016.

LANGREO NAVARRO, A. y CASTILLO VALERO, J.S. (2014). "Estructura, organización y modelos empresariales en el sector". En Compés López, R. y Castillo Valero, J.S. (coord.): La economía del vino en España y en el mundo, pp. 141-174. Almería: Cajamar Caja Rural.

MAGRAMA (varios años). La Alimentación en España. Madrid: Servicio de Publicaciones del Ministerio de Agricultura, Alimentación y Medio Ambiente.

MAGRAMA (varios años). Datos de las Denominaciones de Origen Protegidas de Vinos (DOPS). Madrid: Servicio de Publicaciones del Ministerio de Agricultura, Alimentación y Medio Ambiente.

MERCASA (varios años). Alimentación en España. Producción, industria, distribución y consumo. Madrid: Empresa Nacional Mercasa.

OBSERVATORIO ESPAÑOL DEL MERCADO DEL VINO (OEMV) (2016). Exportaciones de vino y mosto por Comunidades Autónomas, año 2015. Madrid: OEMV. 
OBSERVATORIO ESPAÑOL DEL MERCADO DEL VINO (OEMV) (2016). Exportaciones de vino de Castilla y León, 2015. Madrid: OEMV.

SÁNCHEZ HERNÁNDEZ, J.L. (2014). "El valor social y territorial del vino en España". En Compés López, R. y Castillo Valero, J.S. (coord.): La economía del vino en España y en el mundo, pp. 31-66. Almería: Cajamar Caja Rural.

SANZ CAÑADA, J. (1993). Industria agroalimentaria y desarrollo regional. Madrid: Ministerio de Agricultura, Pesca y Alimentación, Serie Estudios, $\mathrm{n}^{\circ} 78$.

UNWIN, T. (2001). El vino y la viña. Geografía histórica de la viticultura y el comercio del vino. Barcelona: Tusquets.

ZANNI, L. (2004). Leading firms and wine clusters. Understanding the evolution of the Tuscan wine business through an international comparative analysis. Milán: Franco Angeli. 